\title{
EL IMPACTO ELECTORAL DE LAS REFORMAS ECONÓMICAS EN AMÉRICA LATINA (1982-1995)
}

\section{Carlos Gervasoni*}

¿De qué manera reaccionaron los votantes latinoamericanos frente a las distintas políticas económicas implementadas luego de la crisis de la deuda de 1982? ¿Apoyaron o se opusieron al número creciente de gobiernos que aplicaron reformas económicas de mercado? A pesar de que existe una literatura considerable acerca de los efectos del desempeño económico sobre los resultados electorales, especialmente en las democracias industriales (por ejemplo LewisBeck, 1990), pero también en América Latina (Remmer, 1991), no se ha desarrollado demasiado trabajo empírico referente a la relación entre política económica y resultados electorales '. Muchos influyentes académicos aceptaron por muchos años la tesis convencional, no corroborada empíricamente, de que los votantes latinoamericanos tienden a rechazar las administraciones reformistas.

Este artículo se propone evaluar los efectos de políticas económicas alternativas sobre el apoyo electoral a presidentes democráticamente electos en América Latina luego del estallido de la crisis de la deuda. Se intenta responder el siguiente interrogante: ¿qué estrategia económica fue electoralmente más conveniente para las administraciones gobernantes? ¿El modelo ortodoxo y de libre mercado defendido por la mayoría de los economistas, o el enfoque heterodoxo y estatista asociado al estructuralismo, el populismo y el socialismo? La evidencia empírica que se presenta revela, en contra de las expectativas de gran parte de la literatura, una asociación nula o positiva (es decir, nunca negativa) entre las políticas ortodoxas y de libre mercado y el desempeño electoral de las administraciones gobernantes.

\section{TEORÍAS ALTERNATIVAS SOBRE EL IMPACTO ELECTORAL DE LA ESTABILIZACIÓN Y LAS REFORMAS ESTRUCTURALES}

Desde la década del '70, muchos estudiosos de América Latina han sostenido que las políticas económicas ortodoxas eran "políticamente impracticables" debido a las "enormes tensiones sociales que creaban” (O’Donnell, 1973). En los años posteriores a la cesación de pagos en que incurrió México en agosto de 1982 y que desató la crisis de la deuda latinoamericana, era un supuesto común en el debate inte- lectual y político la idea de que las políticas ortodoxas y de libre mercado eran políticamente insostenibles bajo regímenes democráticos, particularmente en un contexto de marcado deterioro de las condiciones económicas. Se pensaba que la estabilización y la reforma estructural sólo eran viables bajo gobiernos autoritarios:

Muchos cientistas políticos consideran que las políticas económicas clásicas u ortodoxas pueden ser impuestas sólo por regímenes no democráticos. Más allá de lo deseables que puedan ser las políticas económicas de libre mercado -y ni siquiera existe consenso sobre este punto-, no se debería esperar que los gobiernos democráticos las apliquen debido al daño sustancial que causan en el corto plazo. Esta noción prevalece particularmente entre los expertos en política latinoamericana. Desde el desarrollo de la descripción "burocrática-autoritaria" de fines de los '70, muchos expertos han asumido que sólo tales regímenes pueden soportar la presión política que resulta inevitablemente de la percibida dureza de las soluciones económicas clásicas (Lynch 1994, 101; traducción del autor).

Según esta línea de pensamiento, los ajustes fiscales, las privatizaciones, la competencia externa, la desregulación y la liberalización de los precios provocan aumentos del costo de vida, recesión, desempleo, pobreza y concentración de riqueza. Bajo estas condiciones, los gobiernos que aplicaran reformas pro-mercado serían derrotados electoralmente en la primera oportunidad. Adam Przeworski, por ejemplo, ha sostenido: "Cualesquiera que sean sus consecuencias de largo plazo, en el corto plazo las reformas suelen causar

Universidad Católica Argentina y Universidad Torcuato Di Tella. El origen de este artículo es una tesis de maestría presentada ante el Center for Latin American Studies, Stanford University (Gervasoni 1995). Agradezco a George Avelino, Paige Bierma, Graciela Ducatenzeiler, Barbara Geddes, Terry Karl, Chappell Lawson, Eduardo Lizano, Raúl Madrid, Manuel Mora y Araujo, Guillermo O’Donnell, Robert Packenham, Clark Reynolds, Doug Rivers, Sybil Rhodes, Florencia Schindler, Philippe Schmitter, John Williamson y Rubén Zamora por su colaboración, comentarios y sugerencias.

1. Weyland (1996) es una interesante excepción, basada en cinco casos sudamericanos. 
inflación, desempleo y mala asignación de los recursos, además de generar cambios volátiles en los ingresos relativos. Estas no son consecuencias políticamente populares en ningún lugar. Y bajo tales condiciones, la democracia en el ámbito político funciona contra las reformas económicas." Algunas páginas más adelante Przeworski agrega: "Aún cuando la ciudadanía apoya el tratamiento radical al principio, los limitados datos con que contamos indican que este apoyo se desgasta, a menudo drásticamente, a medida que se experimentan los costos sociales. La oposición se expresa en encuestas de opinión pública, elecciones, huelgas y, a veces, disturbios" (Przeworski, 1991:161 y 167, traducción y subrayado del autor). En un paper posterior, Przeworski y Stokes sostuvieron:

Cualquiera que sean sus resultados en el largo plazo, las reformas económicas aplicadas actualmente en varios países alrededor del mundo generan una declinación inmediata del consumo en amplios segmentos de sus poblaciones. Por lo general estas reformas responden a un shock externo cuyas consecuencias persisten (Brada y King 1992), y que inducen un desempleo temporario del capital y la mano de obra, la quiebra de empresas y una desorganización gerencial transicional (Blanchard et al., 1991; Przeworski 1991). Más aún, estas políticas afectan la distribución del ingreso, variando la participación relativa de categorías particulares dentro y fuera de la fuerza de trabajo. Debería esperarse sobre fundamentos a priori, así como se observa en la realidad, que tales políticas provoquen una resistencia política generalizada (1993, 1; traducción del autor) ${ }^{2}$.

Los supuestos detrás de estas teorías eran (1) que las reformas económicas ocasionarían, al menos en el corto plazo, mayores costos que beneficios, y (2) que los perjudicados se opondrían a las reformas, incluso votando en contra de las administraciones reformistas. Algunos académicos vinculados con la influyente CEPAL constituyen un ejemplo de quienes sostenían la primera hipótesis:

Debemos considerar los dramáticos efectos recesivos y regresivos de los experimentos neoliberales de ajuste estructural. El énfasis en la reducción del gasto agregado para alcanzar una mínima estabilidad macroeconómica y desequilibrios externos manejables provocó una aguda declinación de la producción, alto desempleo y fuertes recortes de los salarios reales... Así, los sectores más pobres han empeorado su situación y las posibilidades de crecimiento futuro han sido seriamente amenazadas (Sunkel y Zuleta, 1990: 49; traducción del autor).

Barbara Geddes resume con precisión la segunda hipótesis:

Las expectativas ex ante se presentaban aproximadamente así: la liberalización económica tendrá costos en el corto plazo para el sector popular urbano, especialmente la mano de obra organizada. Los trabajadores responderán con huelgas, manifestaciones, y votos en contra de los políticos que iniciaron las políticas de ajuste. En consecuencia, los gobernantes no querrán asumir el riesgo de iniciar políticas impopulares ya que, de hacerlo, perderán la siguiente elección y sus políticas serán revertidas (1995: 199, traducción y subrayado del autor).

Basándose en estos supuestos, muchos académicos realizaron predicciones pesimistas acerca del destino electoral de las administraciones reformistas de la región (sobre la administración Aylwin, véase Petras, 1991, 156-7; sobre la administración Menem, véase Acuña, 1993: 24). El fracaso de estas predicciones fomentó el desarrollo de teorías alternativas que pusieron en evidencia las debilidades del razonamiento tradicional acerca de la relación entre reformas económicas y comportamiento electoral. Los resultados electorales satisfactorios conseguidos por reformistas tales como Monge en Costa Rica, Paz Estenssoro en Bolivia, Aylwin en Chile, Fujimori en Perú y Menem en Argentina, especialmente cuando se los compara con las derrotas sufridas por gobiernos no reformistas tales como los de Siles Zuazo en Bolivia, Alfonsín en Argentina, García en Perú y Sarney en Brasil, otorgaron mayor credibilidad a la idea de que las políticas ortodoxas de estabilización y reforma estructural podían no ser tan impopulares como se había pensado hasta el momento.

El aparente mejor desempeño económico logrado por los gobiernos reformistas y la reelección de presidentes claramente identificados con políticas pro-mercado dejaron en claro que el paradigma prevaleciente (de aquí en adelante denominado el "paradigma tradicional") tenía, en el mejor de los casos, algunas debilidades. Estas deficiencias condujeron al surgimiento de un nuevo paradigma, que sostenía que las políticas ortodoxas, por medio de la reducción de la inflación y de los desequilibrios externos y del mejoramiento de la asignación de los recursos, logran un mejor desempeño económico; que las economías libres de las distorsiones provocadas por las regulaciones estatales y el proteccionismo atraen más inversión y, por lo tanto, crecen más rápidamente, y que las privatizaciones a menudo resultan en mejores servicios públicos para más gente. Finalmente, se enfatizó que las bajas tasas de inflación típicamente asociadas con políticas monetarias y fiscales rigurosas generan gran apoyo por parte de la población, ya que elevan el poder adquisitivo de las familias de ingresos bajos. De acuerdo con este nuevo paradigma, todos estos beneficios sumados podrían compensar con creces los costos de las reformas y, consecuentemente, generar aceptables niveles de apoyo electoral para las administraciones reformistas. A comienzos de

2. En un artículo más reciente, Stokes, Przeworski y Buendía Laredo, basándose en datos macroeconómicos y de opinión pública de tres países (Polonia, Perú y México), arriban a una conclusión algo diferente, esto es, que las reformas económicas no siempre producen oposición generalizada: "Bajo condiciones democráticas hay más margen de apoyo a reformas socialmente costosas y, al mismo tiempo, más base racional para oponerles resistencia de lo que se suele suponer. Cuando las penurias que traían aparejadas pudieron ser justificadas, y cuando no llegaron a ser catastróficas ni se prolongaron eternamente, las reformas obtuvieron apoyo" (1997, 53, subrayado del autor). 
los '90 algunos investigadores del tema comenzaron a sostener tesis como las siguientes: "existe evidencia de que las políticas reformistas exitosas pueden generar apoyo electoral significativo" (Krueger, 1993: 31; traducción del autor); "los costos de la liberalización o son menores o están distribuidos más complejamente que lo que se asumió inicialmente" (Geddes, 1995: 203; traducción del autor); y “aún cuando los costos fueron extremadamente altos, los gobiernos no siempre fueron rechazados en las urnas" (Geddes, 1995: 205; traducción del autor). En el que probablemente sea el primer estudio empírico acerca de la relación entre políticas reformistas y resultados electorales en países en vías de desarrollo, Joan Nelson concluyó que de 16 "Intensively Adjusting Governments," 6 obtuvieron la reelección y 2 más lograron “cuasi-victorias," mientras que 5 fueron derrotados y 3, "cuasi-derrotados" (1992: 254-255). El hecho de que aproximadamente la mitad de las administraciones reformistas en tres continentes (América Latina, Asia y Africa) hayan sido electoralmente exitosas constituyó un serio desafío para el paradigma tradicional. Refiriéndose específicamente a América Latina, David Hojman ha sostenido que "la oposición popular a las PEALM (políticas económicas abiertas de libre mercado) ha sido pequeña excepto en Venezuela. En algunos casos, el apoyo popular a las PEALM parece ser fuerte (Argentina, México y Perú). En Chile, el apoyo es abrumador. El común de la gente parece desaprobar la inflación alta de forma mucho más contundente de lo que algunos académicos han creído" (1994, 218; traducción mía). Más recientemente, la hipótesis de que las reformas ortodoxas producen más costos que beneficios, particularmente en el corto plazo, ha sido más enérgicamente objetada: "Los hechos no sostienen tal pesimismo frente a una reacción demorada. Una vez que se tiene en cuenta la probabilidad de que el hecho contrario - no reforma- produce resultados aún peores en el corto plazo, las consecuencias de una reforma son en realidad auspiciosas"(Rodrik, 1996: 29; traducción del autor).

Considerando esta literatura más reciente, se plantea aquí la siguiente hipótesis: en los países latinoamericanos en la década del '80 y en la primera mitad de los'90, las políticas económicas ortodoxas y de libre mercado no estuvieron asociadas con un desempeño electoral peor por parte de los presidentes de la región que las politicas heterodoxas y estatistas (a igualdad de otros factores). En otros términos, se hipotetiza que las políticas ortodoxas y de libre mercado condujeron a las administraciones que las aplican a resultados electorales iguales o mejores que los que obtuvieron las que sustentaron políticas heterodoxas y estatistas. Contrariamente al paradigma tradicional, se intenta probar que los votantes latinoamericanos no castigaron (y pueden haber apoyado) a las administraciones reformistas.

Antes de desarrollar la contrastación empírica de esta hipótesis, presento un marco analítico de las relaciones que existen entre política económica, desempeño económico y desempeño electoral, resumido en la figura I.

En el modelo, la política económica influencia el desempeño electoral mediante su impacto sobre variables que miden el desempeño económico (tales como el crecimiento y la inflación) y a través de Otras variables (3) diferentes del

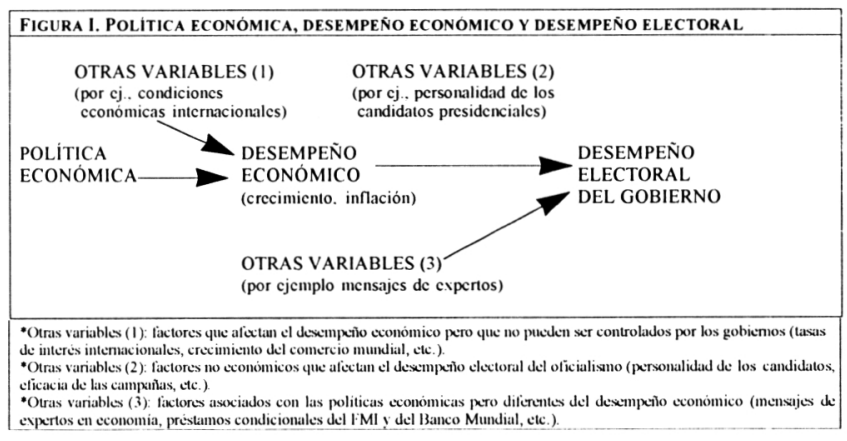

desempeño económico. Este es, a su vez, afectado por Otras variables (1) no relacionadas con la política económica. Finalmente, el desempeño electoral también es afectado por Otras variables (2) no relacionadas con la política económica. La hipótesis a verificar se concentra en el impacto general de la política económica sobre el desempeño electoral de los partidos gobernantes. Los efectos específicos de indicadores de desempeño económico y de variables no económicas, tales como los mensajes de los líderes de opinión, son brevemente tratados pero no contrastados directamente en este artículo. Estos efectos constituyen temas de gran interés y relevancia para futuras investigaciones.

\section{METODOLOGÍA}

Para verificar la hipótesis, se operacionalizaron las variables electoral y de política económica, y se identificaron las administraciones que se encontraban en las condiciones necesarias para ser incluidas en este estudio. Luego de recolectar y procesar los datos apropiados, se los analizó mediante varios modelos de regresión múltiple por mínimos cuadrados de la variable electoral sobre las cuatro variables de política económica.

\section{Definición de variables}

Con finalidades de claridad conceptual, se han dividido a las políticas económicas en dos dimensiones: la macroeconómica y la institucional-estructural ${ }^{3}$. La dimensión macroeconómica es definida por las políticas fiscales y monetarias. La ortodoxia significa que el presupuesto estatal se encuentra balanceado o que es superavitario, y que la oferta monetaria crece a un ritmo lento, compatible con el crecimiento de la demanda de dinero y de la producción, y con la estabilidad de los precios. Una administración se transforma en heterodoxa cuando incurre en déficits fiscales y aumenta la tasa de crecimiento de la oferta monetaria. La dimensión institucional-estructural se define por la dicotomía estadomercado. En esta dimensión, el liberalismo o el neoliberalismo implican que los medios de producción pertenecen

3. “El ajuste realizado por las naciones generalmente abarca dos aspectos diferentes aunque entrelazados: la estabilización; es decir, reducir los déficits de la balanza de pagos y la inflación a niveles compatibles con un crecimiento sostenido (...) a través de medidas fiscales y monetarias generalmente acompañadas por la devaluación (...) y el cambio estructural diseñado para (...) mejorar los incentivos y la eficiencia en pos de un crecimiento sostenido" (Nelson (ed.), 1990: 3-4; traducción del autor). 
a los ciudadanos o a instituciones privadas, y que las decisiones económicas son tomadas principalmente por compañías privadas y los consumidores a través de los mecanismos del mercado. El estatismo tiene lugar cuando el estado es dueño de una proporción importante de los medios de producción y cuando las decisiones económicas son tomadas por burócratas o por mercados distorsionados por la intervención estatal.

La estabilización se refiere a la aplicación de políticas fiscales y monetarias ortodoxas con el objeto de eliminar desequilibrios tales como los déficits fiscal y de la cuenta corriente y, en última instancia, la inflación. Así, la estabilización corresponde a un desplazamiento desde la heterodoxia hacia la ortodoxia en la dimensión macroeconómica. Nótese que la reducción de la inflación a través de otros métodos, como el congelamiento de precios y salarios, no puede ser llamada estabilización. Es en este sentido que los planes antinflacionarios implementados a mediados de los ' 80 en Argentina (Plan Austral) y en Brasil (Plano Cruzado) son normalmente llamados "heterodoxos".

El término reforma estructural significa un movimiento desde instituciones y arreglos económicos estatistas hacia otros basados en el libre mercado. Las reformas estructurales más comunes son la apertura del comercio exterior, las privatizaciones, las desregulación de precios, la liberalización de los mercados financieros y laborales, y la racionalización del estado.

En las economías latinoamericanas, típicamente desequilibradas y estatistas, la ortodoxia generalmente implica estabilización (y la heterodoxia su ausencia), mientras que el liberalismo implica las reformas estructurales (y el estatismo su ausencia). En muy pocos casos (siendo la administración de Aylwin en Chile el ejemplo más claro) la ortodoxia y el liberalismo no se traducen necesariamente en estabilización o reforma estructural, ya que el régimen anterior había comenzado y casi finalizado dichos procesos. En un caso como este, la ortodoxia y el liberalismo implican mantener las políticas vigentes.

Dado que la dimensión macroeconómica involucra básicamente dos políticas, monetaria y fiscal, se han definido dos variables con el objeto de medir esta dimensión: crecimiento de la oferta monetaria (COM) y déficit fiscal (DF). Como indicador del crecimiento de la oferta monetaria se eligió la tasa anual de crecimiento del dinero (M1), expresada en porcentaje ${ }^{4}$ (International Monetary Fund, 1982 a 1996a; 1995b). Fue más difícil encontrar medidas estándar para el déficit fiscal, ya que cada nación organiza sus cuentas nacionales (como así también sus instituciones estatales) de manera distinta. La CEPAL (ECLA 1980 a 1995), por ejemplo, publica medidas diferentes para los distintos países: déficit del gobierno central, déficit del sector público, déficit del sector público no financiero, déficit fiscal, etc. Idealmente, se habría utilizado la medida más generalizada del déficit fiscal para todos los países; por ejemplo, el déficit del gobierno central más el de las provincias y los municipios, las empresas públicas, las agencias descentralizadas y el banco central. Sin embargo, la única medida del déficit fiscal comparable en todos los países es el déficit general del gobierno central (Inter-American Development
Bank, 1994 y 1995). Obviamente, este indicador es muy limitado ya que no abarca los niveles inferiores de gobierno, las compañías estatales, etc. Así, como es usual en el caso de las ciencias sociales, este trabajo se basa en parte sobre indicadores imperfectos 5 .

Una advertencia adicional: tanto el déficit fiscal como el crecimiento de la oferta monetaria dependen de otros factores además de la política económica. Un aumento en las tasas de interés internacionales, una recesión cíclica o una sequía pueden intensificar los déficits fiscales. Un ingreso de capital súbito o un mejoramiento significativo en los términos de intercambio pueden causar una expansión de la oferta monetaria. Todos estos factores se encuentran fuera del control del gobierno. Aún así, el déficit fiscal y el crecimiento de la oferta monetaria constituyen indicadores razonables de ortodoxia y heterodoxia por dos razones: primero, porque los factores exógenos sólo explican una parte de la variación del déficit fiscal y del crecimiento de la oferta monetaria, quedando la otra parte (más importante) ligada a las políticas gubernamentales; segundo, porque los gobiernos pueden diseñar estrategias para compensar los factores exógenos (por ejemplo, recortes de presupuesto adicionales, nuevos impuestos, mayores requerimientos de encajes bancarios, esterilización de dinero a través de operaciones en el mercado abierto, etc.). Dicho en otros términos, un gobierno comprometido con la ortodoxia (o heterodoxia) puede mantener los indicadores en un nivel cercano al de sus objetivos, aún en el caso de encontrarse con factores exógenos desfavorables (Easterly and Schmidt-Hebbel, 1994: 33).

Encontrar datos sistemáticos y comparables para la dimensión institucional-estructural fue aún más difícil. El grado de libertad de comercio, financiera o de precios, o el grado de participación del sector privado en la propiedad los medios de producción son variables difíciles de medir, especialmente en una escala intervalar. No existen indicadores simples para estas variables ni publicaciones que sigan sistemáticamente su evolución para todos los países.

4. Se me ha sugerido utilizar la tasa de inflación en vez de la tasa del crecimiento de la oferta monetaria, porque es la inflación la que tiene un impacto electoral (la mayoría de los votantes no están informados acerca de la política monetaria del candidato, pero sí experimentan el aumento en los precios). Aunque es cierto, como se indica más adelante en este artículo, que el crecimiento de la oferta monetaria afecta el desempeño electoral básicamente a través de la inflación; lo que aquí se analiza es la relación entre la política económica y los resultados electorales, no entre el desempeño económico y los resultados electorales. No obstante, debe señalarse que, dada la alta correlación entre el crecimiento de la oferta monetaria y la tasa de inflación, los efectos del primero en el desempeño electo ral reflejarán fundamentalmente el impacto de la inflación. En otros términos, dado que estas dos variables son altamente colineares, utilizar una de ellas significaría inevitablemente medir tanto una política económica como un resultado económico. Cualquier de las dos produciría resul tados similares. Por lo tanto, la atribución del poder explicativo debe realizarse sobre bases no estadísticas, y tanto la teoría como la experiencia manifiestan que es la inflación la que ejerce una influencia directa sobre los votantes (este tema es profundizado en la sección "Ortodoxia fiscal y monetaria, inflación y desempeño electoral").

5. Los estudios comparativos de países sobre temas de política fiscal por lo general se enfrentan con este problema. "Aunque las medidas del déficit basadas en el amplio alcance del sector público son las medidas más precisas de la situación fiscal y de las transferencias del sector público, por lo general éstas no se encuentran disponibles además de generar ciertas controversias.” (Easterly, Rodriguez and Schmidt-Hebbel, 1994: 67; traducción del autor). 
La estrategia fue la de recolectar datos solamente para dos variables asociadas a la dimensión institucional-estructural: el grado de participación del estado en la producción de bienes y servicios, y el nivel de proteccionismo. La privatización ${ }^{6}$ y la liberalización del comercio ${ }^{7}$ probablemente hayan sido las dos reformas estructurales más importantes en América Latina durante los ' 80 y los ' 90 . La presencia de estos dos tipos de reformas se asocia normalmente con la implementación de otras políticas de libre mercado. Tanto la privatización como la liberalización del comercio fueron implementadas en varias naciones; en muchos casos fueron las primeras reformas en realizarse, y han tenido un evidente impacto económico, además de gran visibilidad política. Es por ello que se han realizado varios estudios al respecto, contándose consecuentemente con más y mejores datos.

Debido a que no existen escalas intervalares para estas variables (como sí existen para el déficit fiscal y el crecimiento de la oferta monetaria), se intentó capturar las variaciones en estas políticas creando variables ordinales. Cada gobierno fue clasificado en base a estudios de casos (Gustafson (ed.) 1994; Nelson (ed.) 1990; Smith, Acuña y Gamarra 1994a y 1994b), estudios específicos sobre privatización y liberalización del comercio en América Latina ${ }^{8}$, y clasificaciones ya existentes en la literatura (Williamson 1990a y 1990b; Banco Mundial 1993; Edwards 1995; Johnson y Sheehy 1995). Aunque se corren algunos riesgos al utilizar clasificaciones que se basan en indicadores que no son totalmente objetivos, se tiene un nivel razonable de confianza en que investigadores independientes estarían de acuerdo con la mayoría de los valores asignados (los cuales, además, son presentados en el apéndice).

Respecto al grado de participación del estado en la producción de bienes y servicios, se definieron las siguientes categorías: 1) muy bajo, 2) bajo, 3) moderado, 4) alto y, 5) muy alto. Para ubicar los gobiernos en cada una de estas categorías se analizaron los patrones de propiedad de cuatro sectores: servicios públicos (agua, energía, telecomunicaciones, transporte, etc.), sectores básicos o "estratégicos" (petróleo, acero, hierro, cobre), instituciones financieras, y otras industrias (una amplia categoría incluida en el análisis cuando el estado es propietario de empresas típicamente privadas, tales como hoteles, cemento, pesca, papel, azúcar, tabaco y bebidas alcohólicas). La categoría en que se ubica un gobierno se determina en función de la medida en que cada uno de los cuatro sectores mencionados es dominado por compañías estatales. Específicamente, cada país recibió un puntaje de 1 (participación estatal no significativa) a 5 (participación privada no significativa) en cada sector. Se calculó un promedio ponderado utilizando, en general, los siguientes valores relativos: servicios públicos $=0,4$, sectores bási$\cos =0,3$, instituciones financieras $=0,2$ y otras industrias $=0,1$. Se utilizaron diferentes valores relativos cuando un sector adquiría una importancia desproporcionada en un determinado país (por ejemplo, a los "sectores básicos" les fueron asignados valores más altos en los casos de Chile y Venezuela, donde el cobre y la producción de petróleo, respectivamente, tienen una importancia extraordinaria).

En cuanto al nivel de proteccionismo existen también cinco categorías: 1) régimen de libre comercio, 2) régimen de libre comercio moderado, 3) régimen proteccionista moderado, 4) régimen proteccionista, y 5) régimen muy proteccionista. En este sentido, se observó los aranceles de importación máximos, mínimos y promedio, y las barreras no arancelarias tales como tipos de cambio múltiples, cuotas y prohibiciones. Además, se tomó en cuenta la pertenencia a una asociación de libre comercio o a una unión aduanera. Los puntajes fueron asignados por un sistema similar al descripto para la variable propiedad estatal de los medios de producción. En términos de pesos relativos, el criterio más importante fue el arancel promedio, seguido por la cobertura de las barreras no arancelarias. Se les asignó menores pesos relativos a las tarifas máximas y mínimas, y a la pertenencia a algún esquema de integración económica.

Los cuatro indicadores fueron medidos al final de cada administración para otorgar un cierto margen de tiempo a las políticas elegidas para ser implementadas y ejercer algún efecto. Cuando la elección que indica la finalización de un gobierno tiene lugar en la segunda mitad del año, se utilizaron cifras para el déficit fiscal del año de la elección (E1) y del año inmediatamente posterior: Cuando la elección ocurre en la primera mitad del año, se recurrió al déficit fiscal de los dos años inmediatamente precedentes al año de E1. Así, el déficit fiscal se calculó como el promedio del déficit total del gobierno central en esos dos años. El crecimiento de la oferta monetaria fue transformado en una nueva variable, elevándola a la potencia - 0,3 (la usual transformación logarítmica falló en la eliminación de su severo sesgo positivo). Esta transformación fue necesaria por razones prácticas (la existencia de algunos valores extremadamente altos; ver apéndice) y por razones teóricas (el hecho de que se espera que aumentos similares en $\mathrm{M}_{1}$ tengan efectos menores a medida que el nivel absoluto del crecimiento de la oferta monetaria crece). Por ejemplo, se espera que un aumento en la tasa de crecimiento de la oferta monetaria del $3 \%$ al $10 \%$ tenga un impacto mucho mayor en el desempeño electoral del que un aumento similar del 100\% al 107\%".

6. “Es este énfasis en la privatización lo que distingue las reformas estructurales recientes de los esfuerzos previos por desregular las economías latinoamericanas. La privatización, más que cualquier otra política, cambió el escenario económico en América Latina" (Edwards, 1995: 170; traducción mía)

7. "Las reformas de liberalización del comercio (...) tal vez constituyan el aspecto más profundo del proceso de transformación” (Edwards, 1995: 11; traducción mía)

8. Para el nivel de proteccionismo se recurrió a Agosin (1992), Agosin y French-Davis (1993), Asad y Rajapatirana (1993), Canitrot y Junco (eds.) (1993), Dean, J., Seema, D. y Riedel J. (1994), Edwards (1994a y 1994b), U.S. Department of State (1989) y the Country Profiles y Country Reports de The Economist Intelligence Unit. Respecto al grado de participación estatal en la producción de bienes y servicios, recurrí a Baer (1994), Baer y Birch (1992), Baer y Birch (eds.) (1994), Devlin (1993), Glade (ed.) (1986 y 1991), Kelly de Escobar (comp.) (1985), Lieberman (1994), Sanchez y Corona (eds.) (1993), Wortman 1990, Latin Finance (1991-1995, 1991, 1995 a y 1995b) y the Reports y Profiles de The Economist Intelligence Unit.

9. Esta expectativa es confirmada por los datos recolectados para este artículo: el análisis estadístico muestra que la relación entre el crecimiento de la oferta monetaria y la variable dependiente es claramente nolineal, y que utilizar transformaciones con potencias moderadamente negativas de aquélla hace la relación lineal y más fuerte. El poder predictivo de los modelos estadísticos presentados más adelante en el artículo se ve enormemente mejorado por la transformación del crecimiento de la oferta monetaria. El modelo 1 en la tabla IV, por ejemplo, tiene un R2 ajustado del 0,71 pero, si el crecimiento de la oferta monetaria no es transformado, cae a 0,43 . 
Esta variable fue calculada para el año de la elección cuando la misma se realizó en la segunda mitad del año. Si la elección tuvo lugar en la primera mitad, entonces se utilizó el crecimiento de la oferta monetaria para el año anterior a la elección.

Para construir la variable dependiente, el desempeño electoral de cada gobierno, se utilizaron datos referidos a las elecciones presidenciales (en contraposición a las elecciones legislativas) ya que, generalmente, es la figura del presidente la que se ve castigada o recompensada respecto a los asuntos nacionales tales como la economía. Además, las elecciones presidenciales se ven afectadas por los matices locales en menor medida que las elecciones legislativas, y son más fácilmente comparables entre países.

La variable dependiente, el desempeño electoral del partido o coalición en el poder, fue medida utilizando la variación en el voto por el oficialismo (VVO) como indicador. $\mathrm{La}$ VVO fue definida a través de la siguiente ecuación:

$$
\mathrm{VVO}=\mathrm{V} 1-\mathrm{V} 0 \text { donde }
$$

VVO es la variación en el voto por el oficialismo,

$V_{0}$ es el porcentaje de los votos válidos obtenidos por el partido ganador ${ }^{10}$ (o coalición) en (la primera rueda de) una elección presidencial (E0),

V1 es el porcentaje de los votos válidos obtenidos por el mismo partido (o coalición) en la (primera rueda de la) siguiente elección presidencial (E1).

La VVO, entonces, es la diferencia entre el porcentaje de los votos válidos obtenidos por un partido o una coalición gobernante en dos elecciones presidenciales consecutivas. La VVO es negativa cuando el desempeño electoral del gobierno declina entre E0 y E1, y positiva cuando su desempeño mejora entre E0 y E1. Se eligió este indicador porque es simple e intuitivo, y porque ya ha sido utilizado en la literatura (Remmer, 1991).

\section{Muestra}

El universo de este estudio está constituido por todos los gobiernos latinoamericanos elegidos en comicios razonablemente limpios desde 1982, y para los cuales una segunda elección presidencial había ocurrido hasta el 30 de junio de 1995. Estas condiciones son reunidas por 30 gobiernos en 15 países.

El caso de Cuba fue dejado de lado ya que no realizó ninguna elección competitiva durante ese período. El gobierno de Sarney en Brasil no fue incluido porque no fue popularmente elegido. En tres instancias en que se efectuaron elecciones formalmente competitivas, la magnitud del fraude electoral descalificó el caso: México en 1988, Paraguay en 1989, y República Dominicana en 1994. Hubo otros casos en que se alegó un fraude significativo, pero en los que no hay certeza de que haya ocurrido (Nicaragua en 1984, República Dominicana en 1990 y El Salvador en 1984, 1989 y 1994). Imitando a Remmer en su preferencia por "errar en el sentido de la inclusividad" (Remmer, 1991: 780), estos casos fueron incluidos en la muestra. La administración de Endara en Panamá fue excluida debido a que los resultados de las elecciones de 1989, anulados por Noriega, fueron sólo en parte recuperados después de la invasión de los EE.UU.

Dos casos particularmente difíciles son los de Pérez en Venezuela y Collor en Brasil. Ambos presidentes fueron sometidos a juicio político bajo cargos de corrupción, declarados culpables y destituidos de sus cargos. Sus períodos fueron completados por líderes que no se identificaban con los presidentes enjuiciados. Sería metodológicamente incorrecto tratar de igual manera a los presidentes que completaron sus períodos que a los que sólo gobernaron parte de los suyos. Sin embargo el criterio de selección podría ser cuestionado si se descartara estos casos, dado que los defensores del paradigma tradicional frecuentemente invocan las administraciones de Collor y Pérez (particularmente la última) para ilustrar la impopularidad de las políticas ortodoxas y de libre mercado"

Con el objeto de testear la hipótesis propuesta rigurosamente, se analizaron los datos de ambas formas: incluyendo

\begin{tabular}{|c|c|c|c|c|c|c|}
\hline \multicolumn{7}{|c|}{ 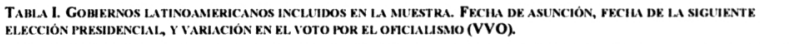 } \\
\hline Pais & Presidencia & Partido ${ }^{\prime}$ & $\begin{array}{l}\text { Fecha de } \\
\text { asunción }\end{array}$ & \begin{tabular}{|l|} 
Fechade \\
siguiente elección
\end{tabular} & VVo & $\begin{array}{c}\text { VVO } \\
\text { (Remmer) }\end{array}$ \\
\hline Argentina & $\begin{array}{l}\text { Alronsin } \\
\text { Menem }\end{array}$ & $\begin{array}{l}\mathrm{UCR} \\
\mathrm{PJ}\end{array}$ & $\begin{array}{l}12 / 83 \\
7 / 89\end{array}$ & $\begin{array}{l}5 / 89 \\
5 / 95\end{array}$ & $\begin{array}{l}-19.3 \\
2.5\end{array}$ & 19.3 \\
\hline Bolivia & $\begin{array}{l}\text { Siles Zuazo } \\
\text { Paz Estenssoro } \\
\text { Paz Zamora }\end{array}$ & $\begin{array}{l}\text { UIDP } \\
\text { MNR } \\
\text { MIR }\end{array}$ & $\begin{array}{l}10 / 82 \\
8 / 85 \\
8 / 89\end{array}$ & $\begin{array}{l}7 / 85 \\
5 / 89 \\
5 / 93\end{array}$ & $\begin{array}{l}-2.0 \\
-4.6 \\
.10\end{array}$ & -20.9 \\
\hline Brasil & Collor ${ }^{3}$ & PRN & 390 & $100 / 44$ & .30 .5 & \\
\hline Colombia & \begin{tabular}{|l|} 
Belancur \\
Barco \\
Gaviria \\
\end{tabular} & $\begin{array}{l}\mathrm{PC} \\
\mathrm{PL} \\
\mathrm{PL}\end{array}$ & $\begin{array}{l}88182 \\
8886 \\
8990\end{array}$ & $\begin{array}{l}5 / 86 \\
5 / 90 \\
5 / 94\end{array}$ & $\begin{array}{l}-11.0 \\
-10.0 \\
-3.1\end{array}$ & $\begin{array}{l}-11.0 \\
-10.7\end{array}$ \\
\hline Costa Rica & \begin{tabular}{|l} 
Monge \\
Arias \\
Calderón
\end{tabular} & $\begin{array}{l}\text { PLN } \\
\text { PLN } \\
\text { PUSC }\end{array}$ & $\begin{array}{l}5 / 82 \\
5 / 86 \\
5 / 90\end{array}$ & $\begin{array}{l}2 / 86 \\
2 / 90 \\
2294\end{array}$ & $\begin{array}{l}-6.5 \\
-5.1 \\
-3,9\end{array}$ & $\begin{array}{l}-6.5 \\
-7.9\end{array}$ \\
\hline Chile & \begin{tabular}{|l} 
Aylwin \\
\end{tabular} & CD & 3900 & $12 / 93$ & 2.8 & - \\
\hline R. Dominicana. & \begin{tabular}{|l|} 
Blanco \\
Balaguer
\end{tabular} & 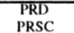 & $\begin{array}{l}8 / 82 \\
8 / 86\end{array}$ & $\begin{array}{l}5 / 86 \\
5 / 90\end{array}$ & $\begin{array}{l}-7.5 \\
-5.9\end{array}$ & $\begin{array}{l}-16.7 \\
-5.2\end{array}$ \\
\hline Ecuador & $\begin{array}{l}\text { Febres } \\
\text { Boria }\end{array}$ & $\begin{array}{c}\text { PSC } \\
\text { ID }\end{array}$ & 8 & $\begin{array}{l}1 / 88 \\
1192\end{array}$ & $\begin{array}{l}-12.5 \\
-163\end{array}$ & $.15,3$ \\
\hline EI Salvador & $\begin{array}{l}\text { Duarte } \\
\text { Cristiani }\end{array}$ & $\begin{array}{c}\text { PDC } \\
\text { ARENA }\end{array}$ & $\begin{array}{l}6684 \\
6 / 89\end{array}$ & $\begin{array}{l}3 / 89 \\
3 / 94\end{array}$ & $\begin{array}{l}-6.9 \\
-4.5\end{array}$ & $-7,4$ \\
\hline Guatemala & Cerezo & DCG & $1 / 86$ & $11 \times 0$ & -21.1 & . \\
\hline Honduras & \begin{tabular}{|l} 
Suazo \\
Azcona \\
Callejas
\end{tabular} & $\begin{array}{l}\mathrm{PH} \\
\mathrm{PM} \\
\mathrm{PN}\end{array}$ & $\begin{array}{l}1 / 82 \\
1 / 86 \\
1 / 90\end{array}$ & $\begin{array}{l}11 / 85 \\
11 / 89 \\
11 / 93\end{array}$ & $\begin{array}{l}-2.9 \\
-6.7 \\
-10.8\end{array}$ & $\begin{array}{l}-3.1 \\
-7,2\end{array}$ \\
\hline \begin{tabular}{|l|l} 
Nicaragua \\
\end{tabular} & Orlega & FSLN & $1 / 85$ & 2900 & -26.2 & -25.5 \\
\hline Perú & $\begin{array}{l}\begin{array}{l}\text { García } \\
\text { Fujimori }\end{array} \\
\end{array}$ & $\begin{array}{l}\text { PAP } \\
\text { C90 }\end{array}$ & $\begin{array}{l}7785 \\
7990\end{array}$ & $\begin{array}{l}4 / 90 \\
4 / 95\end{array}$ & $\begin{array}{l}-30.5 \\
35.6\end{array}$ & .265 \\
\hline \begin{tabular}{|l|l|} 
Uruguay \\
\end{tabular} & $\begin{array}{l}\text { Sanguinetti } \\
\text { Lacalle }\end{array}$ & $\begin{array}{l}\mathrm{PC} \\
\mathrm{PN}\end{array}$ & $\begin{array}{l}3 / 85 \\
3 / 90\end{array}$ & $\begin{array}{l}11 / 89 \\
3 / 95\end{array}$ & $\begin{array}{l}-10,9 \\
-7.8\end{array}$ & $-10,9$ \\
\hline Venezuela & $\begin{array}{l}\text { Lusinchi } \\
\text { Ṕ́rez }^{3}\end{array}$ & $\begin{array}{l}\mathrm{AD} \\
\mathrm{AD}\end{array}$ & $\begin{array}{l}2 / 84 \\
2 / 89\end{array}$ & $\begin{array}{l}12 / 88 \\
12 / 93\end{array}$ & $\begin{array}{l}-5,4 \\
-29,4\end{array}$ & $-4,3$ \\
\hline \multicolumn{7}{|c|}{ 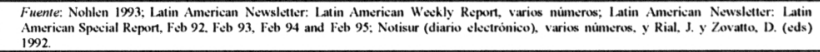 } \\
\hline 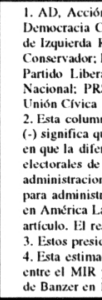 & 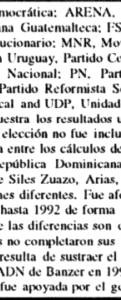 & 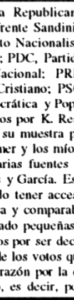 & 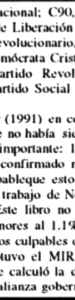 & 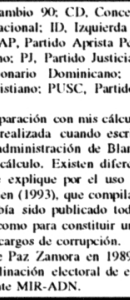 & 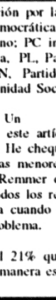 & 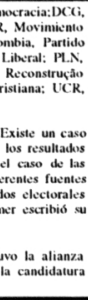 \\
\hline
\end{tabular}

10. El adjetivo "ganador" es usado en el sentido del partido o coalición que obtiene la presidencia. Es necesario aclarar esto porque existen sistemas electorales que pueden hacer que gane un candidato que no sea el que "ganó" en el sentido de obtener más votos (o más votos en la primera ronda). Fujimori, por ejemplo, perdió contra Vargas Llosa en la primera ronda, pero ganó la presidencia en la segunda. En Bolivia, Paz Estenssoro fue derrotado por Banzer en 1985, y Paz Zamora por Sánchez de Lozada y Banzer en 1989, pero ambos, Paz Estenssoro y Paz Zamora, fueron elegidos presidentes por una alianza de dos partidos en el Congreso.

11. Pérez y Collor implementaron políticas ortodoxas sólo de manera limitada. Aunque ambos utilizaron la retórica del "Consenso de Washington" y avanzaron en algunas de sus recomendaciones, no lograron demasiado en varias áreas (por ejemplo, ninguno de estos presidentes privatizó los monopolios estatales más importantes). De hecho, no tuvieron el tiempo, la decisión y/o el poder político necesario para implementar muchas de las reformas que proponían. 
y no incluyendo las administraciones de Collor y de Pérez. Utilizando los indicadores de política económica en el final de las administraciones efectivas de estos dos presidentes, se calculó la VVO de manera convencional en el caso del partido de Pérez, y asumiendo un $0 \%$ de votos para el partido de Collor en E1 (porque no se presentó a las elecciones de 1994).

La Tabla I enumera las administraciones que reúnen las condiciones para ser incluidas en la muestra.

\section{ESTIMACIÓN DEL MODELO Y RESULTADOS}

La Tabla II enumera las 30 administraciones incluidas en este estudio con sus respectivas VVO, ordenadas de menor a mayor (más la media y la mediana de la VVO).

\begin{tabular}{|c|c|c|c|c|c|}
\hline \multicolumn{6}{|c|}{$\begin{array}{l}\text { TABLA II. VARIACIÓN EN EL VOTO POR EL OFICIALISMO (VVO) NO ESTANDARIZADA Y } \\
\text { ESTANDARIZADA PARA } 30 \text { ADMINISTRACIONES LATINOAMERICANAS, 1982-1995. }\end{array}$} \\
\hline Presidencia & VVO & $\begin{array}{c}\text { VVO } \\
\text { estandarizada } \\
\text { (puntaje Z) }\end{array}$ & Presidencia & VVO & $\begin{array}{c}\text { VVO } \\
\text { estandarizada } \\
\text { (puntaje Z) }\end{array}$ \\
\hline García & -30.5 & -1.67 & Mediana & $-7,2$ & \\
\hline Collor & $-30,5$ & $-1,67$ & Duarte & $-6,9$ & 0,20 \\
\hline Pérez & $-29,4$ & $-1,58$ & Azcona & $-6,7$ & 0,21 \\
\hline Ortega & $-26,2$ & $-1,33$ & Monge & $-6,5$ & 0,23 \\
\hline Siles Zuazo & $-23,0$ & $-1,07$ & Balaguer & $-5,9$ & 0,28 \\
\hline Cerezo & $-21,1$ & $-0,92$ & Lusinchi & $-5,4$ & 0,32 \\
\hline Alfonsín & -19.3 & $-0,78$ & Arias & $-5,1$ & 0,32 \\
\hline Borja & $-16,0$ & $-0,52$ & Paz Estenssoro & $-4,6$ & 0,34 \\
\hline Fcbres & $-12,5$ & $-0,24$ & Cristiani & $-4,5$ & 0,38 \\
\hline Betancur & $-11,0$ & $-0,13$ & Calderón & $-3,9$ & 0,39 \\
\hline Sanguinetti & $-10,9$ & $-0,12$ & Gaviria & $-3,1$ & 0,44 \\
\hline Callejas & $-10,8$ & $-0,11$ & Suazo Córdoval & $-2,9$ & 0,50 \\
\hline Barco & $-10,0$ & $-0,05$ & Paz Zamora & $-1,0$ & 0,66 \\
\hline Media & $-9,4$ & & Menem & 2,5 & 0,94 \\
\hline Lacalle & $-8,7$ & 0,13 & Aylwin & 2,8 & 0,96 \\
\hline Blanco & $-7,5$ & 0,15 & Fujimori & 35,6 & 3,53 \\
\hline \multicolumn{6}{|c|}{ Finemer Ser Tabla L. } \\
\hline
\end{tabular}

Estos cálculos de por sí ya reflejan resultados interesantes. Las administraciones con VVO más negativas (o desempeños electorales más pobres) incluyen a las más estatistas y heterodoxas que se han registrado en América Latina en los últimos años. García en Perú y Ortega en Nicaragua aplicaron las políticas más claramente estatistas de la región. Siles Zuazo en Bolivia y Alfonsín en Argentina, aunque en menor medida, condujeron gobiernos de escasa disciplina fiscal y monetaria, y casi sin intentos de reforma estructural. Cerezo en Guatemala adoptó un camino similar, aunque en este caso las políticas fiscal y monetaria fueron más ortodoxas. En este grupo también se encuentran a Collor y Pérez. $\mathrm{Si}$ bien es cierto que estos presidentes comenzaron a implementar programas de estabilización y reforma estructural ortodoxos, el motivo principal de sus VVOs fuertemente negativas parecen haber sido los juicios políticos por corrupción que los desalojaron del poder y desprestigiaron a sus partidos. En otras palabras, sólo los gobiernos heterodoxos y estatistas o los gobiernos que colapsaron bajo cargos de corrupción sufrieron declinaciones electorales agudas.

No menos interesante resulta observar qué gobiernos lograron VVOs positivas o, en otras palabras, qué presidentes consiguieron que sus partidos obtengan más votos en las elecciones del final del período que en las elecciones presidenciales anteriores. El caso más destacado es el de Fujimori, que es por lejos el más desviado de la muestra (García y Collor se encuentran a 1,67 desvíos estándar por debajo de la media, Fujimori está a 3,53 desviaciones estándar por enci- ma de la misma) ${ }^{12}$. Un desempeño electoral tan destacado sólo puede explicarse por múltiples factores actuando al mismo tiempo. Seguramente variables no económicas, como el éxito en la lucha contra Sendero Luminoso y el efecto rally round the flag producido por las escaramuzas fronterizas con Ecuador, explican parcialmente semejante ascenso electoral. Sin embargo, en el contexto de la crítica realizada aquí al argumento convencional que afirma que la ortodoxia redunda en desempeños electorales pobres, es de gran relevancia el hecho de que Fujimori implementó durante su primer mandato uno de los programas de reformas económicas ortodoxas más profundos de la región.

Las otras dos administraciones que lograron mejorar sus desempeños electorales, las de Aylwin y Menem, son también ejemplos de políticas de libre mercado. Chile es desde hace años el país más ortodoxo y liberal de América Latina, tanto bajo el gobierno de Pinochet como bajo el de Aylwin. Argentina, durante la primera administración de Menem, implementó un amplio programa de reformas económicas ortodoxas que bien podría reclamar el título del más rápido del mundo. Finalmente, es de destacar que otros presidentes reconocidamente reformistas, como Paz Estenssoro y Paz Zamora de Bolivia, Gaviria de Colombia, Calderón Fournier de Costa Rica y Cristiani de El Salvador, registran VVOs claramente superiores a la media.

$\mathrm{El}$ análisis de las correlaciones bivariadas entre la VVO y los cuatro indicadores de política económica (tabla III) también respalda la hipótesis: existe una asociación negativa entre cada indicador y el desempeño electoral; es decir, a mayor heterodoxia y estatismo, menor apoyo en las urnas. Los coeficientes de las variables macroeconómicas (déficit fiscal y crecimiento de la oferta monetaria) son significativos en niveles de confianza del $95 \%$ y $99 \%$, respectivamente, mientras que los coeficientes del nivel de proteccionismo y del grado de participación del estado en la producción de bienes y servicios son significativos en un nivel del $90 \%$. No obstante, estos resultados se ven limitados por el hecho de que cabría esperar una asociación importante entre las cuatro variables de política económica, dada la tendencia a implementar la reforma en "paquetes" ${ }^{13}$, y por la existencia de otras variables independientes relevantes que podrían modificar los efectos de las variables de política económica.

12. El hecho de que la administración de Fujimori es un caso desviado severo en la distribución de la VVO significa que también podría ser un caso desviado o una observación influyente si se la incluye en un análisis multivariado.

13. Los datos confirman esta expectativa. La siguiente matriz seña la los coeficientes de correlación para las cuatro variables de política económica.

DF COM-0,3 Proteccionismo Participación estatal

\begin{tabular}{lllll}
\hline DF & 1,00 & & & \\
COM-0,3 & 0,23 & 1,00 & & \\
Proteccionismo & $0,39^{*}$ & $-0,05$ & 1,00 & \\
Participación estatal & $0,37^{*}$ & 0,20 & $0,58^{* *}$ & 1,00 \\
\hline
\end{tabular}

$\therefore$ valor $\mathrm{p}<0,01$

* valor $\mathrm{p}<0,05$

Todos los coeficientes menos uno son positivos, y en tres de seis casos alcanzan significancia estadística. 
TABLA III. CORRELACIONES ENTRE LA VARIACIÓN EN EL YOTO POR EL OFICIALISNO (VVO) I CUATRO INDICADORES DE POLITICA ECONÓNICA ( $\mathrm{N}=29$ ).

\begin{tabular}{|l|c|c|c|c|}
\hline & Déficit fiscal & $\begin{array}{c}\text { Crecimiento de la } \\
\text { oferta monetaria }\end{array}$ & Proteccionismo & $\begin{array}{c}\text { Grado de } \\
\text { participación estatal }\end{array}$ \\
\hline VVO & $-0,38$ & $-0,65$ & $-0,31$ & $-0,33$ \\
& $(0,044)$ & $(0,000)$ & $(0,098)$ & $(0,078)$ \\
\hline $\begin{array}{l}\text { Nota: Las entradas son cocficientes de correlación no estandarizados (valores p entre paréntesis). Fujimori no } \\
\text { cstá incluido. }\end{array}$ \\
\hline
\end{tabular}

Consecuentemente, la contrastación rigurosa de la hipótesis requiere de análisis multivariado. Se llevó a cabo un análisis de regresión múltiple por mínimos cuadrados de la VVO sobre los cuatro indicadores de política económica ${ }^{14}$, incluyéndose algunas variables de control teóricamente relevantes y pasibles de ser medidas con precisión. Así, se usó una variable dicotómica para las administraciones que enfrentaron guerras civiles (definidas como cualquier conflicto político violento interno significativo). Esta variable fue codificada con el número 1 cuando existía tal conflicto al final de una administración (Colombia, Guatemala, Nicaragua, El Salvador bajo Duarte y Perú bajo García), y con un 0 en caso contrario. Así, la categoría de base identifica las administraciones que no enfrentaron un conflicto armado, o que lo finalizaron o redujeron substancialmente a través de negociaciones (Cristiani) o de represión (Fujimori). Se incluyeron también una variable dicotómica para el éxito en solucionar una hiperinflación heredada de la administración previa y otra para el fracaso en la misma cuestión. Estas dos variables dicotómicas dividen la muestra en tres tipos de administraciones: las que no heredaron una situación de hiperinflación ( 26 de 30 casos), las que sí la heredaron y fueron exitosas al eliminarla (las administraciones de Fujimori, Menem y Paz Estenssoro), y las que fallaron en la misma situación (la administración de Collor). La última variable de control es el crecimiento del producto bruto mundial ${ }^{15}$, una medida que busca capturar el efecto electoral de las mejores o peores condiciones económicas internacionales.

Cuando el modelo es especificado de esta forma, el caso desviado (Fujimori) aparece también como una observación influyente. Su distancia de Cook, la mayor entre todos los casos, es de 0,82, una cifra cercana al límite absoluto de 1 y muy por encima de la media de todas las distancias de Cook $(=0,077)$ y del punto de corte ajustado por tamaño de la muestra (4/n=0,133; ver Hamilton 1992, 132). Cuando se excluye el caso de Fujimori, la mayor distancia de Cook cae abruptamente a 0,24. Si Fujimori es incluido en un modelo sin Collor ni Pérez, su distancia de Cook es aún mayor: 1,12. Dichoen otros términos, siempre que se incluye al gobierno de Fujimori, éste aparece como una observación influyente. La Tabla IV muestra, por las razones metodológicas explicadas, los resultados de las regresiones para las muestras con y sin Fujimori, y con y sin Collor y Pérez.

El modelo 1 se basa en 27 casos porque excluye aquellas tres administraciones. El resultado más relevante es el de la variable monetaria, ya que posee un gran efecto que es altamente significativo. El aumento en una unidad de la variable crecimiento de la oferta monetaria se asocia, en promedio, con una pérdida del $27 \%$ del total de los votos. Por ejemplo, un gobierno que termina su período con una tasa anual de crecimiento de la oferta monetaria del 3\% obtendría, manteniendo constantes el resto de las variables, casi

\begin{tabular}{|c|c|c|c|c|}
\hline \begin{tabular}{l|} 
VARIABLES \\
INDEPENDIENTES
\end{tabular} & $\begin{array}{c}\text { MODELO I } \\
(\mathrm{N}=27)\end{array}$ & $\begin{array}{c}\text { MODELO } 2^{\top} \\
(\mathrm{N}=28)\end{array}$ & $\begin{array}{c}\text { MODELO } 3^{2} \\
(\mathrm{~N}=29)\end{array}$ & $\begin{array}{c}\text { MODELO } 4^{3} \\
(\mathrm{~N}=30)\end{array}$ \\
\hline Constante & $\begin{array}{c}-19,03 * * * \\
(5,56)\end{array}$ & $\begin{array}{l}-16,59 \\
(10,01)\end{array}$ & $\begin{array}{c}-22,60 * * * \\
(7,70)\end{array}$ & $\begin{array}{l}-20,43^{*} \\
(11,38)\end{array}$ \\
\hline Délicit Fiscal & $\begin{array}{l}-(0,62 * * \\
(0,26) \\
\end{array}$ & $\begin{array}{l}-0,88^{*} \\
(0,46) \\
\end{array}$ & $\begin{array}{c}-0,50 \\
(0,36) \\
\end{array}$ & $\begin{array}{l}-0,76 \\
(0,53) \\
\end{array}$ \\
\hline $\begin{array}{l}\text { Crecimiento de la } \\
\text { oferta monctaria } \\
\text { (a la potencia -(0,3) }\end{array}$ & $\begin{array}{c}-27,03 * * * \\
(5,30)\end{array}$ & $\begin{array}{l}-24,02 * * \\
(9,55)\end{array}$ & $\begin{array}{c}-27,39 * * * \\
(7,43)\end{array}$ & $\begin{array}{l}-24,26 * * \\
(10,96)\end{array}$ \\
\hline Proteccionismo & $\begin{array}{c}-2,14 * * \\
(0,86)\end{array}$ & $\begin{array}{l}-1,05 \\
(1,53)\end{array}$ & $\begin{array}{l}-2,32 * \\
(1,21)\end{array}$ & $\begin{array}{l}-1,19 \\
(1,76)\end{array}$ \\
\hline Participación estatal & $\begin{array}{c}0,85 \\
(1,28)\end{array}$ & $\begin{array}{c}1,50 \\
(2,30)\end{array}$ & $\begin{array}{l}-0,03 \\
(1,77)\end{array}$ & $\begin{array}{c}0,56 \\
(2,61) \\
\end{array}$ \\
\hline $\begin{array}{l}\text { Hiperinflación } \\
\text { derrotada }\end{array}$ & $\begin{array}{c}2,40 \\
(4,26)\end{array}$ & $\begin{array}{c}18,35 * * * \\
(6,41)\end{array}$ & $\begin{array}{c}0,37 \\
(5,92)\end{array}$ & $\begin{array}{l}16,93 * * \\
(7,33)\end{array}$ \\
\hline $\begin{array}{l}\text { Hipcrinflación no } \\
\text { derrotada }\end{array}$ & + & + & $\begin{array}{c}-12,21^{*} \\
(6,93)\end{array}$ & $\begin{array}{l}-14,58 \\
(10,23)\end{array}$ \\
\hline $\begin{array}{l}\text { Crecimiento del PBI } \\
\text { mundial }\end{array}$ & $\begin{array}{c}1,35 \\
(1,43)\end{array}$ & $\begin{array}{l}-(0,47 \\
(2,54)\end{array}$ & $\begin{array}{r}3,20 \\
(1,92)\end{array}$ & $\begin{array}{l}1,50 \\
(2,79)\end{array}$ \\
\hline Guerra civil & $\begin{array}{l}-3,21 \\
(2,19)\end{array}$ & $\begin{array}{l}-3,84 \\
(3,95)\end{array}$ & $\begin{array}{l}-2,42 \\
(3,05)\end{array}$ & $\begin{array}{l}-3,00 \\
(4,52)\end{array}$ \\
\hline $\mathrm{R}^{2}$ Ajustado & 0,71 & 0,53 & 0,57 & 0,46 \\
\hline \multicolumn{5}{|c|}{ 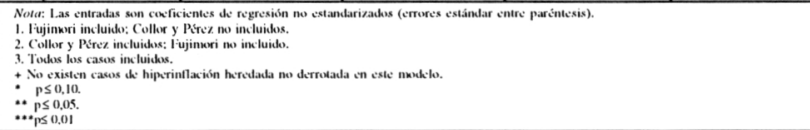 } \\
\hline
\end{tabular}

un $10 \%$ más de votos que otra administración que finaliza su período con una tasa del $30 \%$. Una tasa de crecimiento de la oferta monetaria del $3000 \%$ (sólo posible en una situación de hiperinflación) implicaría que una administración recibiera un $17 \%$ menos de votos que la administración más ortodoxa. El déficit fiscal también posee un efecto significativo en la dirección contraria al paradigma tradicional. Un aumento del déficit fiscal del $1 \%$ del PBI se asocia a una declinación electoral del 0,62\%: se espera que una administración con un superávit fiscal del $2 \%$ del PBI obtenga, a igualdad de otros factores, un $4,34 \%$ más de votos que otra con un déficit del $5 \%$, aún luego de haber controlado por el crecimiento de la oferta monetaria. Es importante destacar que la considerable correlación bivariada entre el déficit fiscal y la declinación electoral (tabla III) se debilita al introducir la variable crecimiento de la oferta monetaria. De hecho, el déficit fiscal posee un coeficiente más alto en cualquier modelo que no incluya el crecimiento de la oferta monetaria. Una posible interpretación de este resultado es que, dado que los déficit presupuestarios son una de las principales causas de la creación de dinero, particularmente en los países menos desarrollados, los mismos afectan a la VVO en parte a través del crecimiento de la oferta monetaria.

El proteccionismo también alcanza significancia estadística en la dirección opuesta a lo previsto por el paradigma tradicional: un movimiento de una categoría a la siguiente más proteccionista se asocia a una pérdida electoral del $2,14 \%$. Una administración con un "régimen de comercio muy proteccionista" (código 5) obtendría un 8,56\% menos votos que una administración con un "régimen de libre

14. Todos los modelos de regresión presentados en este artículo buscan estimar varios coeficientes mediante una muestra relativamente pequeña. La consecuencia estadística de esta situación es que los errores estándar tienden a ser amplios y, por lo tanto, los niveles de significancia de 0,05 o más son difíciles de alcanzar. Muchos coeficientes de regresión que aparecen como estadísticamente no significativos podrían perfectamente serlo en una muestra más grande. Es por ello que se reportan también niveles de significancia de 0,10 y más.

15. Este indicador se tomó del IMF (1995c). Se define como el porcentaje anual del crecimiento del PBI mundial para el año de la elección, si tuvo lugar en la segunda mitad del año, o para el año previo en caso contrario. 
comercio" (código 1), a igualdad de otros factores. Los gobiernos proteccionistas, entonces, reciben considerablemente menos votos que los identificados con la apertura económica. El coeficiente de regresión del grado de participación del estado en la producción de bienes y servicios es el único cuyo signo es consistente con la hipótesis convencional. Sin embargo, el efecto de esta variable es pequeño y está muy lejos de alcanzar significancia estadística.

Como se preveía, el modelo 1 muestra coeficientes positivos para el éxito en la derrota de la hiperinflación heredada y el crecimiento del producto bruto mundial, y negativos para el fracaso en la terminación de una guerra civil. Ninguno de estos coeficientes, sin embargo, logra significancia estadística.

En el modelo 2, en donde se agrega el caso de Fujimori, todos los coeficientes aumentan sus errores estándar y la mayoría obtienen menor significancia. Sólo el coeficiente para la derrota de la hiperinflación se hace más significativo (y mucho mayor) ${ }^{16}$. Aún así, el coeficiente para la variable monetaria sigue siendo muy grande y significativo. El déficit fiscal es significativo sólo para un nivel del 0,10, y el proteccionismo pierde significancia. Es importante notar que aún con todos estos cambios, ninguna de las cuatro variables de política económica cambia de signo o alcanza significancia estadística en la dirección esperada por el paradigma tradicional. Básicamente estos dos modelos dicen que lo que es electoralmente importante es mantener la oferta monetaria bajo control (y, por lo tanto, la inflación baja) y, en menor medida, el presupuesto equilibrado, dos de los principales postulados de la ortodoxia económica. El desempeño electoral se ve o perjudicado (modelo 1) o no influenciado (modelo 2), pero nunca mejorado, por un régimen comercial proteccionista.

El hecho de que una sola observación produzca algunos cambios importantes entre los modelos 1 y 2 ilustra el punto señalado anteriormente: la administración de Fujimori, un caso desviado en términos de VVO, es además una observación influyente. Probablemente esto se deba a las extraordinarias circunstancias que rodean a esta (y sólo a esta) administración, tales como sus resonantes triunfos en la lucha contra la guerrilla, el efecto rally round the flag causado por los enfrentamientos militares con Ecuador poco antes de las elecciones, y su relativamente bajo porcentaje de votos en la primera rueda de las elecciones de 1990 ( $\mathrm{al}$ momento de la primera rueda, Fujimori estaba ganando apoyo popular a una elevadísima velocidad: pasó de ser un desconocido pocas semanas antes de la elección, a lograr una victoria aplastante en la segunda rueda unas semanas más tarde). Estos hechos explican por qué el desempeño electoral de Fujimori fue mucho más satisfactorio del que podría haber sido previsto por un modelo basado en los otros 27 casos. Las regresiones que incluyen este caso (mode$\operatorname{los} 2$ y 4) deben ser o desechadas o interpretadas cuidadosamente y haciendo referencia a modelos sin problemas de influencia (como el modelo 1).

Así, la tabla IV muestra un tercer modelo que no incluye a Fujimori pero sí, los dos gobiernos que concluyeron vía juicio político. Como fue aclarado en la sección metodológica, existen varias razones para no utilizar estos casos en que las administraciones no completaron sus períodos, y en donde la popularidad de los presidentes se vio deterioradas por notorios escándalos de corrupción. Sin embargo, dado que estos casos son frecuentemente considerados como evidencia a favor del paradigma tradicional, se decidió estimar un modelo que incluye estos dos casos y que no controla por la variable juicio político exitoso. Los juicios políticos pueden ser interpretados como las causas de la pobre evolución electoral de los partidos de Collor y de Pérez, o como las consecuencias de sus políticas económicas supuestamente impopulares. Manteniendo el principio de errar en favor del paradigma tradicional, no se utiliza una variable para el juicio político exitoso. El efecto estadístico de esta decisión es el de trasladar al menos una parte de la explicación de las estrepitosas declinaciones electorales de Collor y Pérez desde los escándalos de corrupción hacia sus políticas económicas.

Ocurren pocos cambios con respecto al modelo 1 cuan do se agregan las administraciones de Collor y de Pérez en el modelo 3 (sin Fujimori). Los coeficientes del déficit fiscal, el crecimiento de la oferta monetaria y el proteccionismo casi no cambian, aunque el déficit fiscal pierde significancia estadística. El fracaso en controlar una hiperinflación heredada se asocia a un deterioro electoral significativo (a un nivel de significancia del 0,10 ), reflejando la inclusión de la administración de Collor, el único caso en dicha situación de la muestra. Ninguno de los otros coeficientes obtiene significancia (aunque el crecimiento del producto bruto mundial casi lo logra). El punto principal es que, nuevamente, ninguno de los cuatro indicadores de política económica adquiere significancia estadística en la dirección esperada por el paradigma tradicional. Más aún, ninguno de ellos siquiera apunta en esa dirección aún cuando se consideran las administraciones de Collor y de Pérez. Dicho en otros términos, el modelo 3 mantiene la orientación general del modelo 1: los resultados electorales satisfactorios están asociados con una oferta monetaria controlada, con el libre comercio y con presupuestos equilibrados (estaúltima variable es significativa en el modelo 1 pero no en el 3), y no asociados con el grado de participación del estado en la producción de bienes y servicios.

Finalmente, el modelo 4 incluye los 30 casos. Los resultados son muy similares a los del modelo 2 , pero algo debilitados en términos de significancia estadística a raíz del caso influyente de Fujimori. Aún así, tres de los cuatro indicadores de política económica mantienen signos opuestos al paradigma tradicional, y el único que no lo hace, el grado de participación del estado en la producción de bienes y servicios, exhibe un coeficiente muy pequeño y muy distante de la significancia estadística. En resumen, ninguno de los

16. Es sorprendente que el coeficiente de la derrota de la hiperinflación no sea consistentemente alto y significativo. Uno esperaría que las administraciones que logran terminar con una crisis hiperinflacionaria reciban un "premio" electoral (cosa que ocurre sólo cuando se incluye en el análisis el caso de Fujimori). Las razones de la falta de consistencia parecen ser la distribución sesgada de la variable (la mayoría de las administraciones no enfrentaron hiperinflaciones, quedando sólo algunas pocas en las dos categorías restantes) y el hecho de que parte de las recompensas electorales asociadas con el éxito en el control de la hiperinflación pueden ser capturadas por las variables monetarias y fiscales. 
cuatro modelos provee sustento empírico a la tesis del castigo electoral a los presidentes ortodoxos y orientados hacia el libre mercado ${ }^{17}$.

Los resultados de los modelos en la tabla IV, sin embargo, presentan un problema de temporalidad. Las administraciones más heterodoxas y electoralmente fracasadas (Alfonsín, García, Ortega y Siles) ejercieron la presidencia durante la económicamente crítica década del ' 80 , mientras que las administraciones más ortodoxas y exitosas electoralmente (Aylwin, Fujimori y Menem) pertenecen a la primera mitad de los' 90 . Este hecho sugiere que las conclusiones de la tabla IV pueden derivar de una correlación espúrea, donde la variable realmente relevante es el tiempo (como un indicador las condiciones económicas y financieras internacionales). Aunque los resultados de la tabla IV están controlados por el crecimiento del producto mundial, es posible que otros factores, tales como la situación de los mercados financieros en los ' 80 , hayan al mismo tiempo desalentado las políticas de reforma estructural y estabilización y contribuido al pobre desempeño electoral de los gobiernos de ese momento. La mejora de los mercados financieros al terminar la década habría tanto incentivado las reformas económicas y como contribuido al mejor desempeño electoral de aquellos gobiernos. De haber sido éste el caso, se esperaría que los coeficientes de la tabla IV cambiaran al ser aplicados a las administraciones cuyos períodos finalizaron antes de la mencionada mejora de los mercados de capital a partir de 1990. En otros palabras, se esperaría que la estabilización y las reformas estructurales hayan estado asociadas a un peor desempeño electoral de los gobiernos entre 1982 y 1990, no a uno mejor.

La tabla $\mathrm{V}$ compara el modelo 3 para todas los gobiernos con el mismo modelo aplicado sólo a los 17 que realizaron elecciones presidenciales hasta el 30 de junio de 1990 ${ }^{18}$. La mayoría de los coeficientes son similares en ambos modelos. La variable fiscal posee un impacto mayor y más significativo en el modelo de los' 80 , mientras que el proteccionismo es un poco menos negativo y pierde significancia. El crecimiento de la oferta monetaria mantiene un coeficiente similar y obtiene un error estándar menor. Sólo el coeficiente del crecimiento del producto mundial registra un cambio importante, aunque continúa siendo no significativo estadísticamente. Es decir, el modelo es sustancialmente el mismo cuando es aplicado sólo a aquellas administraciones que tuvieron que sortear las desfavorables condiciones económicas de los '80. Esto implica que, aún durante esos años críticos, la ortodoxia fiscal y monetaria fueron recompensadas electoralmente, yla apertura comercial y las privatizaciones no fueron castigadas. Es decir que aún durante la "década perdida" de crisis y penurias económicas en América Latina, ningún coeficiente adquiere significancia en la dirección de la hipótesis de autores como Przeworski y Stokes.

Una última advertencia con respecto a los resultados de la tabla IV: el gran impacto del crecimiento de la oferta monetaria en todos los modelos puede ser explicado en parte por un problema de endogeneidad o causación de dos vías. Es posible que los presidentes cuyos partidos enfrentan perspectivas electorales sombrías elijan incrementar la oferta monetaria para reactivar la economía a medida que

\begin{tabular}{|c|c|c|}
\hline \multicolumn{3}{|c|}{$\begin{array}{l}\text { TABLA V. REGRESION DE LA VARIACIÓN EN EI, VOTO POREL, } \\
\text { OFICIALISMO (VVO) SOBRE VARIABLES DE POLITICA } \\
\text { ECONÓMICA. 1982-1995 Y } 1982-1990 \text {. ESTIMACIÓN POR } \\
\text { MÍNIMOS CUADRADOS. }\end{array}$} \\
\hline VARIABLES & \multicolumn{2}{|c|}{ MODELO 3} \\
\hline INDEPENDIENTES & $(1982-1995)$ & $(1982-1990)$ \\
\hline Constante & $\begin{array}{c}-22,60^{* * *} \\
(7,70)\end{array}$ & $\begin{array}{l}-11,51 \\
(12,83)\end{array}$ \\
\hline Déficit fiscal & $\begin{array}{l}-0,50 \\
(0,36)\end{array}$ & $\begin{array}{c}-0,69 * * \\
(0,27)\end{array}$ \\
\hline $\begin{array}{l}\text { Crecimiento de la oferta monetaria } \\
\text { (a la potencia - } 0,3)\end{array}$ & $\begin{array}{c}-27,39 * * * \\
(7,43)\end{array}$ & $\begin{array}{c}-25,08^{* * *} \\
(4,91)\end{array}$ \\
\hline Proteccionismo & $\begin{array}{l}-2,32^{*} \\
(1,21)\end{array}$ & $\begin{array}{c}-1,84 \\
(1,10)\end{array}$ \\
\hline Participación estatal & $\begin{array}{l}-0,03 \\
(1,77)\end{array}$ & $\begin{array}{c}0,97 \\
(2,24)\end{array}$ \\
\hline Hiperinflación derrotada & $\begin{array}{c}0,37 \\
(5,92) \\
\end{array}$ & $\begin{array}{c}1,72 \\
(5,32) \\
\end{array}$ \\
\hline Hiperinflación no derrotada & $\begin{array}{c}-12,21 * \\
(6,93)\end{array}$ & + \\
\hline Crecimiento del PBI mundial & $\begin{array}{c}3,20 \\
(1,92)\end{array}$ & $\begin{array}{l}-0,72 \\
(2,12)\end{array}$ \\
\hline Guerra Civil & $\begin{array}{l}-2,42 \\
(3,05) \\
\end{array}$ & $\begin{array}{l}-3,75 \\
(2,36) \\
\end{array}$ \\
\hline $\mathrm{R}^{2}$ Ajustado & 0,57 & 0,77 \\
\hline $\mathrm{N}$ & 29 & 17 \\
\hline \multicolumn{3}{|c|}{$\begin{array}{l}\text { Nota: Las entradas son coeficientes de regresión no estandarizados (errores } \\
\text { estándar entre paréntesis. } \\
+ \text { No hay casos de hiperinflación heredada no derrotada en este modelo. } \\
* \quad p \leq 0,10 \text {. } \\
* * p \leq 0,05 . \\
* * * p \leq 0,01\end{array}$} \\
\hline
\end{tabular}

se acercan las elecciones. Este problema podría ser resuelto utilizando el método de mínimos cuadrados en dos etapas (two-stage least squares) siempre y cuando el sistema de ecuaciones sea identificado, lo que no ocurre, ya que la ecuación para la VVO incluye todas las variables del modelo. Sin embargo, existen razones para creer que el sesgo de endogeneidad, si es que lo hay, es en este caso reducido. Es generalmente aceptado el hecho de que la fuerte asociación entre inflación y desempeño electoral se debe a una relación causal: los votantes aborrecen la inflación, por lo que votan en contra de las administraciones que no logran mantenerla en un nivel bajo. Como la expansión monetaria se encuentra altamente asociada con la inflación, es poco probable que los gobiernos, al menos en el contexto latinoamericano, elijan una política monetaria expansiva para mejorar su desempeño electoral. Una mirada hacia los casos extremos de heterodoxia monetaria, tales como Alfonsín, García, Ortega o Siles Zuazo, muestra claramente que estos líderes no pretendían ganar apoyo electoral emitiendo moneda; más bien, fueron víctimas de desequilibrios macroeconómicos acumulados que, en el momento de las elecciones, se encontraban fuera de su control. Más aún, una investigación empírica previa sobre este tema (Remmer, 1993), basada en una muestra que se superpone en gran medida con la de este artículo, indica que las administraciones latinoamericanas no han tenido la capacidad de manipular la economía con propósitos electorales y que no se existe un patrón de expansión monetaria antes de la elección presi-

17. Se analizaron figuras de diagnóstico con el objeto de detectar posibles violaciones a los supuestos del análisis de regresión en los cuatro modelos de la tabla IV. Ninguno de ellos manifestó evidencia de heteroscedasticidad, no lineariedad o no normalidad. Sin embargo, los modelos 2 , 3 y 4 incluyen casos con errores muy grandes: las administraciones de Fujimori y de Pérez se encuentran siempre entre 2 y 3 desvíos estándar por encima y por debajo de la media de los residuos, respectivamente. Esta es una de las razones por las que se presentan en la tabla 4 tanto los modelos que incluyen como los que no incluyen estos casos. Comparar todos los modelos ayuda a determinar qué resultados son robustos y cuáles dependen de un determinado caso. Respecto a una posible multicolinearidad, se calcularon tolerancias para todas las variables, sin registrarse ningún caso con tolerancia menor a 0,40 . 
dencial. Analizando las políticas monetarias medidas en base al índice de crecimiento de M1, Remmer afirma:

\begin{abstract}
Simplemente en términos de la dirección de los efectos estimados, ninguno de los siete países para los que se dispone de datos se adapta completamente al patrón cíclico esperado. Además, de los coeficientes de regresión que logran significancia estadística, uno apunta hacia el expansionismo preelectoral, uno sugiere austeridad preelectoral, tres sugieren austeridad postelectoral, y cinco indican expansionismo postelectoral. Así, los resultados son altamente variados, con datos apuntando con igualintensidad en el sentido de la versión contracíclica como en el de la cíclica del political business cycle (397; traducción del autor).
\end{abstract}

El hecho de que estos resultados estadísticos no muestran ningún patrón de expansión o de ajuste monetario antes de las elecciones presidenciales significa que los presidentes vulnerables (la mayoría de ellos, del período 1980-1991 que Remmer analiza) no utilizaron, en general, políticas monetarias laxas como estrategia electoral.

Entonces, los resultados en las tablas IV y V contradicen directamente la hipótesis del paradigma tradicional y proveen algo de apoyo para la hipótesis contraria. En la dimensión macroeconómica queda claro que un manejo ortodoxo de la política monetaria conlleva resultados electorales satisfactorios. Las políticas monetarias laxas se asocian con considerables pérdidas de votos. La razón principal por la que las políticas monetarias heterodoxas son rechazadas en las elecciones es la inflación, como indican el gran coeficiente del crecimiento de la oferta monetaria, junto con la usualmente alta correlación entre el crecimiento de la oferta monetaria y la inflación (para los casos en este artículo, $r$ de Pearson es 0,99 para las variables crudas, y 0,86 para las variables transformadas mediante el uso de una potencia). Las ventajas electorales asociadas con la expansión monetaria (que se supone tiene, al menos en el corto plazo, un efecto de reactivación y de creación de empleos) parecen ser menores que sus costos electorales (causados fundamentalmente por el alza en los precios típicamente asociada con la expansión de la oferta monetaria).

En la dimensión institucional-estructural se evidencian resultados similares, aunque no tan marcados. El proteccionismo se asocia (en dos modelos significativamente y en dos no significativamente) con un peor desempeño electoral, mientras que el grado de participación del estado en la producción de bienes y servicios no posee un efecto estadísticamente significativo sobre la VVO. Estos resultados sugieren la posibilidad de que los costos de abrir la economía e introducir mayor competencia externa (por ejemplo, pérdida de empleos en industrias protegidas) pueden ser menores que sus beneficios (por ejemplo, nuevos trabajos en empresas exportadoras, precios más bajos de los bienes de consumo, bienes intermedios y de capital más baratos y mejores, etc.). También es posible que los costos de la privatización, como los despidos, sean compensados con beneficios tales como mayores ingresos fiscales, servicios públicos mejores y/o más baratos, mayor inversión en infraestructura, etc. No obstante, lo más relevante para la hipótesis de este artículo es que, independientemente del balance entre los costos y beneficios materiales experimentados por los votantes, ni la privatización ni la apertura comercial minaron el apoyo electoral de los gobiernos que las llevaron a cabo (y la liberalización del comercio parece haberlos fortalecido).

Estas observaciones son particularmente llamativas si se las considera desde la influyente perspectiva que asocia las políticas ortodoxas y de libre mercado con la resistencia política. El paradigma tradicional habría predicho que los cuatros indicadores de política económica hubieran tenido probablemente una correlación negativa con la declinación electoral (esto es, cuanto más ortodoxa y de libre mercado la política, peor el desempeño electoral del gobierno). Ciertamente, dicha predicción hubiera sido completamente incorrecta respecto a los países latinoamericanos en los años posteriores a la crisis de la deuda de 1982: ningún indicador refleja un coeficiente significativo en la dirección señalada por el paradigma tradicional. La tabla VI resume en lenguaje no estadístico los hallazgos de la tabla VI:

\begin{tabular}{|c|c|c|c|}
\hline & $\begin{array}{l}\text { Conclació } \\
\text { el desen }\end{array}$ & $\begin{array}{l}\text { entre la política c } \\
\text { peño electoral del }\end{array}$ & $\begin{array}{l}\text { conómica y } \\
\text { gobierno }\end{array}$ \\
\hline Indicadores de política cconómica & $\begin{array}{l}\text { Positivo y significativo } \\
\text { (paradigma tradicional) }\end{array}$ & $\begin{array}{l}\text { No significativo } \\
\text { (hipótcsis nula) }\end{array}$ & $\begin{array}{c}\text { Negativo y signiticativo } \\
\text { (hipótesis alternativa) }\end{array}$ \\
\hline Déficit fiscal & Nunca & Modelo 3 & Modelos 1 y 2 \\
\hline Crecimiento de la oferta monctaria & Nunca & Nuncia & Siempre \\
\hline Proteccionismo & Nunca & Modelo 2 & Modelos I y 3 \\
\hline $\begin{array}{l}\text { Grado de participación del estado } \\
\text { en la producción de hienes y } \\
\text { servicios }\end{array}$ & Nunca & Siempre & Nuncia \\
\hline
\end{tabular}

No obstante, cabe destacar que estas observaciones no se prestan para la generalización. Los resultados fueron obtenidos para una región, América Latina, y para un período de tiempo, 1982-1995. No se aplican necesariamente al pasado o al futuro, o a otras regiones del mundo con antecedentes económicos e ideológicos distintos ${ }^{19}$. De hecho, no sería sorprendente obtener resultados completamente diferentes para las administraciones que gobernaron antes de la crisis de la deuda. Es muy probable que dicha crisis haya marcado un punto crítico en la relación entre la economía y las elecciones en América Latina. La llamada década perdida representó el golpe final a una estrategia económica que venía mostrando signos de agotamiento desde los 60'. Muchos de los factores que explican el mejor desempeño electoral de las administraciones reformistas no estaban presentes, o eran mucho menos importantes, antes de $1982^{20}$.

Una advertencia adicional es que estos resultados sólo se refieren a la relación entre las políticas económicas y la declinación electoral. Aunque el desempeño económico y el equilibrio entre los costos y beneficios sociales fueron intro-

18. Nótese que este modelo es el mismo, más allá de la inclusión o no de las administraciones de Collor, Pérez y Fujimori, dado que ninguna de ellas pertenece a la década del ' 80 .

19. Debe destacarse que se han realizado intentos por demostrar la existencia de apoyo popular a las reformas de mercado en otras partes del mundo (para el caso de Rusia, por ejemplo, véase Duch, 1993).

20. Este es el caso del consenso académico sobre la necesidad de reformas en América Latina, el evidente mejor desempeño económico de Chile con respecto al resto de América Latina, la profundidad de la crisis económica en términos de inflación y de deterioro de la producción, y la creciente toma de conciencia por parte del electorado sobre las deficiencias del modelo económico previo y los méritos de uno nuevo. 
ducidos como variables intervinientes, los datos analizados en este artículo no prueban ni intentan probar que ciertas políticas producen mejores o peores resultados económicos y mejores o peores balances entre costos y beneficios sociales. En otras palabras, que la política A sea más exitosa electoralmente que la política $\mathrm{B}$ en un determinado tiempo y lugar no implica que también sea más eficiente, más justa o éticamente mejor.

\section{EFECTO DE LAS VARIABLES DE CONTROL DE DESEMPEÑO ECONÓMICO}

Hasta aquí, los modelos analizan sólo la relación entre política económica y desempeño electoral de las administraciones, el tema principal de este artículo. Como lo muestra el modelo de la figura I, se supone que las políticas económicas afecten las elecciones en parte a través de variables de desempeño económico (como la inflación y el crecimiento), y en parte mediante otras variables (como los mensajes críticos o de apoyo por parte de expertos que legitiman o deslegitiman cierta estrategia económica). Determinar de manera rigurosa la medida en que las variables de desempeño económico actúan como intermediarios en la relación entre el tipo de política económica y los resultados electorales se encuentra fuera del alcance de este artículo. Ello requeriría un estudio cuantitativo más extenso y complejo, basado en un modelo de ecuaciones estructural con más variables (especialmente, valores retardados de las variables económicas) y con más coeficientes a estimar (por lo que se necesitarían bastante más que 30 casos). Un modo menos detallado pero útil de explorar los efectos de las variables de desempeño económico consiste en estimar un modelo controlado por estas variables, como se puede observar en la última columna de la tabla VII. Los indicadores clásicos del desempeño económico son el crecimiento del PBI, la tasa de desempleo y la inflación. Los últimos dos presentan problemas metodológicos infranqueables que deben tenerse en consideración a la hora de interpretar los resultados del análisis estadístico. El problema referido a la inflación ya ha sido explicado: se encuentra altamente correlacionada con el crecimiento dela oferta monetaria. La severa colinearidad resultante genera errores estándar muy grandes y coeficientes imprecisos. En el caso del desempleo existe un importante problema de medición. Los métodos para calcular la tasa de desempleo y la cobertura geográfica de las encuestas nacionales varían considerablemente de país a país ${ }^{21}$. En la estimación de los modelos de la tabla VII se utilizan las series de desempleo de la CEPAL, bajo el supuesto (probablemente fuerte) de que existe una alta correlación entre las tasas de desempleo reportadas por cada país y la tasa real.

Teniendo presentes estas advertencias, ¿cuál es el efecto de introducir variables de control de desempeño económico? ${ }^{22}$. El cambio más importante es que el crecimiento de la oferta monetaria pierde significancia a raíz del efecto controlador de la inflación, que tiene un coeficiente significativo negativo de gran magnitud. Como se preveía, los errores estándar de estas dos variables son muy amplios debido a la multicolinearidad. Las otras tres variables de desempeño económico producen pocos cambios, aunque el proteccio-

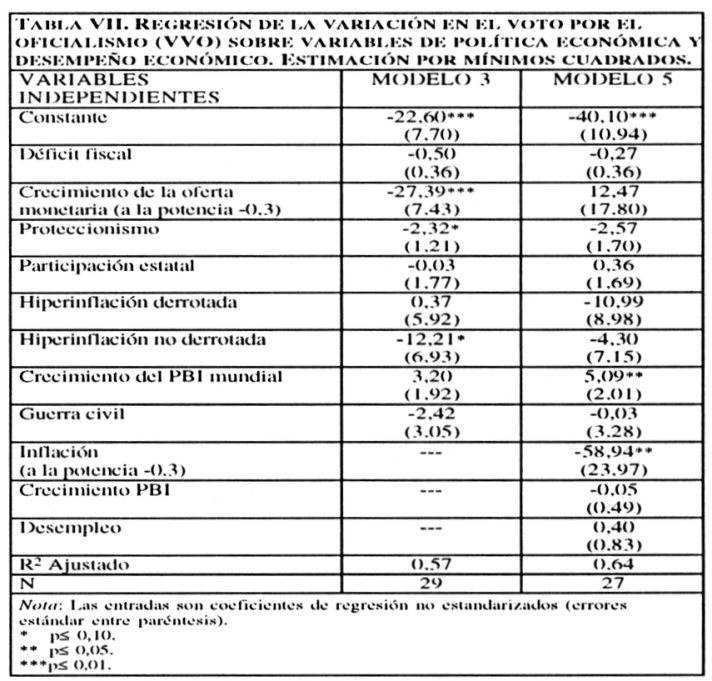

nismo pierde significancia (debido al incremento de su error estándar). Sorprendentemente, dos de las tres variables de desempeño económico no tienen efectos estadísticamente significativos: el crecimiento del PBI y el desempleo no perjudican ni benefician significativamente la fuerza electoral del gobierno. Además de la inflación, el crecimiento del PBI mundial es la única variable con coeficiente significativo: cada punto porcentual adicional del crecimiento de la economía global se asocia a un incremento aproximado del $5 \%$ en el apoyo electoral del partido gobernante en elecciones presidenciales.

La tabla VII, entonces, señala dos hechos importantes: 1) algunos de los efectos electorales beneficiosos de las políticas ortodoxas para el gobierno son mediadas por variables de desempeño económico (claramente, este es el caso de la oferta monetaria y la inflación), y 2) nuevamente, ninguno de los cuatro indicadores de política económica adquiere significancia en la dirección esperada por el paradigma tradicional. Esto destaca la resistencia de los principales resultados empíricos de este artículo a las diferentes especificaciones y controles. En otros términos, los resultados estadísticos de mayor significación teórica de las tablas IV, V y VII son estadísticamente robustos: no se modifican sustancialmente por cambios en la especificación del modelo.

\section{ORTODOXIA FISCAL Y MONETARIA, INFLACIÓN Y DESEMPEÑO ELECTORAL}

En todos los modelos de la tabla IV, el indicador de la oferta monetaria produce el mayor efecto y el más signifi-

21. Los siguientes son algunos de los problemas de utilizar los datos clásicos sobre desempleo (CEPAL): las cifras para El Salvador, Nicaragua y la República Dominicana no se reportaron hasta fines de 1980; algunos países miden el desempleo total, otros el desempleo urbano (lo que implica un sesgo muy grande para países como El Salvador y Ecuador), y otros sólo el índice de desempleo en la capital (también un sesgo enorme para países como Perú); algunos países reportan el desempleo oculto mientras que otros no. Otras fuentes, como los informes del FMI, presentan los mis mos inconvenientes.

22. El modelo 5, que introduce variables de control de desempeño económico, incluye 27 casos, 2 menos que el modelo 3 , ya que no se encontraron algunos datos sobre las administraciones de Blanco y de Balaguer de la República Dominicana (véase ECLA, 1980 a 1997). 
cativo. Dicha variable, consecuentemente, merece un examen más minucioso. Ya se explicó que, aunque conceptualmente diferentes, el crecimiento de la oferta monetaria y la inflación se encuentran -por lo general- altamente correlacionados. Las políticas monetarias laxas producen inflación o convalidan y prolongan la inflación ocasionada por desequilibrios macroeconómicos previos.

Entre las variables de desempeño económico que explican las variaciones en el desempeño electoral del gobierno, la más importante para el período estudiado es la inflación (ver tabla VII), y las políticas fiscales y monetarias ortodoxas han demostrado ser muy efectivas para derrotarla ${ }^{23}$. Los votantes tienen muchas razones para recompensar la estabilidad de los precios: 1) la inflación erosiona el poder adquisitivo de quienes cuentan con ingresos fijos, 2) funciona como un impuesto regresivo, 3 ) obstaculiza la toma de decisiones racionales de consumo, ahorro e inversión y, 4) crea una sensación generalizada de incertidumbre y caos. Además, la inflación provoca efectos perjudiciales indirectos: desalienta la inversión (y, en el largo plazo, el crecimiento), fomenta la fuga de capitales, y reduce los ingresos fiscales mediante el efecto Olivera-Tanzi. Sólo recientemente los académicos han comenzado a reconocer el grado de rechazo popular por la inflación. "En el pasado, algunos políticos en América Latina y académicos en todas partes pueden haber subestimado el daño causado al común de la gente por la alta inflación y la inestabilidad macroeconómica, así como la firmeza con que las víctimas de la inflación la rechazaron" (Hojman, 1994: 213).

Aunque la restricción fiscal y monetaria necesaria para alcanzar estabilidad en los precios normalmente resulta, en el corto plazo, en una desaceleración de la actividad económica, una reducción súbita de las altas tasas de inflación provoca, por lo general, el efecto contrario: la estabilidad de precios, la eliminación del impuesto inflacionario, el cambio en las expectativas del consumidor y el retorno de la inversión externa pueden llegar a producir un boom de consumo y la reactivación de la economía (Rodrik, 1996: 29). Este fue el caso, por ejemplo, de Argentina luego del lanzamiento del "Plan de Convertibilidad", y de Brasil, inmediatamente después de implementar el "Plan Real".

Por lo general, el desempeño económico ha sido conceptualizado fundamentalmente en términos de desempleo y crecimiento. Ciertamente, este es el caso de las democracias industrializadas. Pero aún en esos países, la inflación ha demostrado ser también una variable relevante (Lewis-Beck, 1990: 8-12), aun cuando no varía demasiado. La mayoría de los países desarrollados, durante la mayor parte del tiempo, han mantenido la inflación en niveles moderados. Pero la inflación ha sido mucho más importante en América Latina debido a su volatilidad y niveles elevados. La inflación alta (y aún más hiperinflación) es un fenómeno todavía más visible y socialmente costoso que el estancamiento de la producción, y, a diferencia del desempleo, afecta a todos los votantes. Por lo tanto, el desempeño económico debe incluir a la inflación como un componente relevante ${ }^{24}$.

En la figura II se puede observar la recta de mínimos cuadrados para la regresión simple de la VVO sobre el logaritmo de la tasa de inflación para el año de la elección si tiene lugar en la segunda mitad del año, o para el año previo en caso contrario. Existe una fuerte asociación negativa entre la inflación y el desempeño electoral. El aumento en una unidad en el logaritmo de la inflación está asociado con una declinación electoral de gran magnitud: $8,16 \%$ (valor $\mathrm{p}$ $=0,000$ ). En otras palabras, una administración que finaliza su período con una tasa de inflación del $200 \%$ al año recibiría, con el resto de las factores constantes, un $8,16 \%$ menos de votos que la administración cuya tasa de inflación es del $20 \%$, y del $16,32 \%$ menos que otra con una tasa de inflación del $2 \%$. Esta regresión simple, que no incluye la administración de Fujimori - un caso claramente desviado-, tiene un alto $\mathrm{R}^{2}$ ajustado, del 0,72. Además, si se excluyen los casos de hiperinflación (Alfonsín, García, Ortega y Siles), la pendiente se hace más inclinada $(-9,9)$, lo que puede ser fácilmente visualizado en la figura II (el valor $\mathrm{p}$ de dicha pendiente es 0,0017, y el $\mathrm{R}^{2}$ ajustado 0,35). Es decir, aún si no se cuentan los casos en que la inflación es más obviamente un pasivo electoral para el gobierno (esto es, cuando las elecciones tienen lugar en momentos de hiperinflación), el efecto de la inflación en el desempeño electoral es crítico.

FigURA II. REgRESIÓN DE LA VARIACIÓN EN EL VOTO POR EL OFICIALISMO (VVO) SOBRE EL LOGARTIMO DE LA INFLACIÓN (AÑO ANTARIOS AL DE LAS ELECCIONES PRESIDENCIALES). 27 ADMINISTRACIONES, 1982-1995

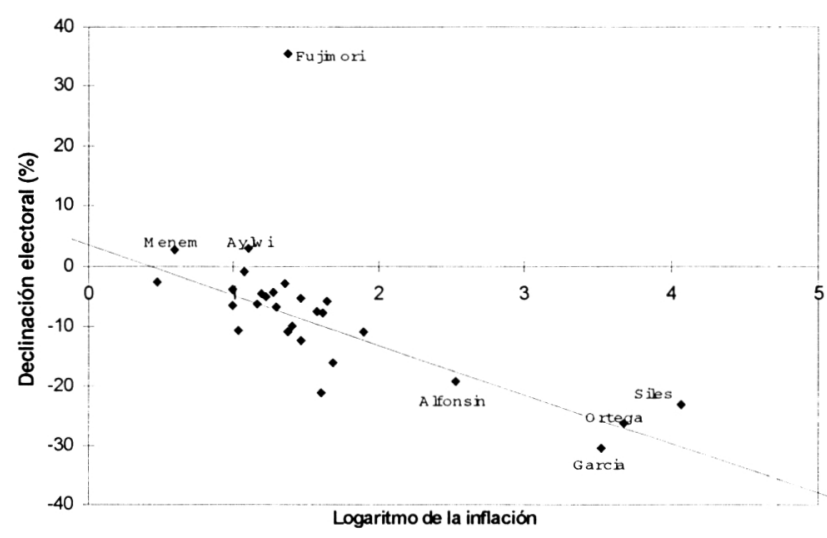

La alta correlación positiva entre el crecimiento de la oferta monetaria y la inflación, y la alta correlación negativa entre la última y la VVO implican que, como se observa en la comparación de ambos modelos en la tabla VII, el alto costo electoral de las políticas monetarias heterodoxas mostrado en la tabla IV se debe básicamente al efecto de la inflación, una variable de desempeño económico crítico en el contexto latinoamericano.

23. "Las políticas fiscales y monetarias son centrales en cuanto a los esfuerzos de estabilización en el corto plazo, más allá de si se aplican también políticas de ingresos u otras medidas heterodoxas" (Haggard and Webb, 1994: 3). "Aún los partidarios de las políticas "heterodoxas" de estabilización que incluyen controles de precios y salarios o el uso de la tasa de cambio a modo de ancla nominal reconocen que tales medidas nunca dieron resultado en ausencia de medidas ortodoxas complementarias de control fiscal y monetario" (Haggard and Kaufman, 1992: 273). “¿Cómo se alcanza la macroestabilidad? Pienso que es lo suficientemente claro que se debe contar con un presupuesto balanceado" (Dornbusch, 1991: 2).

24. Para una perspectiva similar y un mayor desarrollo de este punto, ver Weyland (1996). 


\section{CONCLUSIONES}

Este artículo intenta evaluar la relación entre el tipo de política económica y el desempeño electoral de las administraciones latinoamericanas luego de 1982. La hipótesis propuesta pone en tela de juicio la idea convencional de que las políticas de estabilización y de reforma pro-mercado llevan, en países democráticos, al castigo electoral de las administraciones reformistas.

Para comprobar la hipótesis se escogieron cuatro indicadores de política económica: déficit fiscal, crecimiento de la oferta monetaria, nivel de proteccionismo y grado de participación del estado en la producción de bienes y servicios. La variable dependiente, la variación en el voto por el oficialismo (VVO), fue definida como la diferencia entre el porcentaje de los votos obtenidos por un partido o coalición en una elección presidencial que marca el final de su período y el porcentaje de los votos obtenidos por el mismo partido o coalición en la elección presidencial inmediatamente anterior.

Para analizar los datos se utilizaron modelos de regresión múltiple por mínimos cuadrados. Los indicadores entraron en el modelo de forma lineal, excepto el crecimiento de la oferta monetaria, que fue sometido a una transformación curvilínea para eliminar su marcado sesgo y sus numerosos casos desviados. Se incluyeron en los modelos estadísticos otras variables explicativas relevantes no directamente relacionadas con la hipótesis para evitar problemas de especificación debido a variables omitidas. Una de ellas refleja la existencia de una guerra civil. Dos variables adicionales identifican las administraciones que heredaron una crisis hiperinflacionaria y la solucionaron, y aquellas administraciones que no pudieron solucionar una hiperinflación heredada. Se introdujo un indicador de la situación de la economía internacional, el crecimiento del producto mundial. El modelo también fue estimado controlando por las tres variables clásicas de desempeño económico: crecimiento, desempleo e inflación.

Los resultados arrojados por varias especificaciones alternativas del modelo otorgaron un considerable apoyo a la hipótesis. Una de las variables independientes, el crecimiento de la oferta monetaria, tuvo un efecto ampliamente negativo sobre la dependiente: a mayor heterodoxia monetaria, menor apoyo electoral. Se argumenta, con considerable respaldo empírico, que el crecimiento de la oferta monetaria alimenta la inflación, y que la inflación produce importantes pérdidas de votos al oficialismo. Más aún, la evidencia empírica presentada indica que la inflación ha sido probablemente el factor más importante a la hora de explicar el desempeño electoral de los gobiernos de América Latina entre 1982 y 1995.

Una segunda variable que alcanzó (o casi alcanzó, dependiendo de la especificación del modelo) significancia estadística fue el proteccionismo. Las políticas proteccionistas están asociadas con resultados considerablemente peores que las políticas de libre mercado. Los datos sugieren que uno de los postulados principales del pensamiento económico latinoamericano tradicional, la orientación hacia el mercado interno, ha sido electoralmente inconveniente (o, en el mejor de los casos, electoralmente neutral) en el período estudiado. Por el contrario, la liberalización del comercio y/o las economías abiertas parecen beneficiar (o por lo menos no perjudicar) el desempeño electoral de los gobernantes.

El déficit fiscal también provoca un efecto opuesto al esperado por el paradigma tradicional. Sin embargo, su coeficiente pierde significancia cuando se incluyen los casos de Collor y de Pérez. Por otro lado, el grado de participación del estado en la producción de bienes y servicios tiene, en la mayoría de los modelos, el signo esperado por ese paradigma: a mayor estatismo, mejores resultados electorales. La magnitud de este efecto, no obstante, es siempre muy pequeña y nunca logra significación estadística. La hipótesis nula que afirma que el grado de participación del estado en la producción de bienes y servicios no tiene ningún efecto sobre el desempeño electoral no puede ser rechazada. Entonces, la privatización no parece haber beneficiado ni perjudicado a los gobiernos en términos electorales.

Es interesante observar que estos resultados permanecen prácticamente sin cambios si se incluyen los metodológicamente complicados casos de Collor y Pérez, los ejemplos más citados por los defensores del paradigma tradicional. Cuando se los incluye, el modelo se hace más débil (ver modelo 3 contra el modelo 1 en la tabla IV): todos los coeficientes muestran errores estándar más amplios, y el $\mathrm{R}^{2}$ ajustado disminuye considerablemente. El déficit fiscal, particularmente, que en el modelo 1 y 2 tiene un impacto negativo estadísticamente significativo sobre la VVO, pierde significancia en los modelos 3 y 4 . Ni un solo coeficiente, sin embargo, cambia de signo en la dirección esperada por el paradigma tradicional. Todo lo contrario: el grado de participación empresaria del estado cambia de positivo a negativo.

Estos resultados sugieren que los trabajos previos sobre los efectos de la estabilización y la reforma estructural han tendido a enfatizar sus costos y a minimizar sus beneficios. Estos beneficios incluyen la estabilidad macroeconómica, el crecimiento, la mayor disponibilidad de bienes de consumo, intermedios y de capital importados, más y mejores servicios públicos, grandes aumentos en la productividad, nuevos y mejores empleos en sectores exportadores, etc. También es posible que la literatura se haya concentrado demasiado en los efectos materiales de las reformas en las condiciones económicas de los votantes (el llamado pocketbook vote), sin considerar la creciente evidencia que muestra el mayor poder explicativo de la percepción de los votantes sobre la salud de la economía (el collective economic performance vote) (Lewis-Beck 1990). La mejor situación macroeconómica que crearon las reformas puede haber incentivado a los votantes a apoyar a los gobiernos reformistas aún si su propia situación económica no había mejorado.

Un importante punto teórico aquí es que la liberalización tiene costos, pero estos se concentran generalmente en grupos relativamente pequeños (aunque bien organizados) tales como los trabajadores en industrias protegidas o subsidiadas, los dueños de esas industrias, los empleados públicos, y aún los militares (cuando se les recorta el presupuesto y se privatizan sus fábricas de producción de armamento). Sin embargo, todos estos grupos en conjunto representan 
una pequeña parte del electorado. En la medida en que están organizados pueden ser lobbistas de peso, pero tienen muy poca influencia electoral. Por el otro lado, existen muchos grupos que no se organizan ni actúan en pos de sus intereses sin la intervención de la coerción o incentivos selectivos: "Algunos grupos tales como los consumidores, los contribuyentes, los desempleados y los pobres no cuentan ni con los incentivos ni con el pequeño número necesario como para organizarse, entonces son excluidos de las negociaciones" (Olson, 1982: 37; traducción mía). Los grupos que sí se organizan luchan por una mayor participación en el ingreso nacional a expensas de toda la sociedad. Estas presiones "reducen la eficiencia y el ingreso agregado" y "reducen la tasa de crecimiento económico" (Olson, 1982: 46-47 y 65; traducción mía). Luego de identificar los grupos que generalmente logran organizarse y desarrollar capacidad de lobby (sindicatos, asociaciones de profesionales, gremios empresariales), Olson menciona a los que típicamente no lo hacen: "Los grupos olvidados" están "entre los mayores grupos en la nación, y tienen algunos de los intereses comunes más vitales": trabajadores de cuello blanco, contribuyentes, trabajadores golondrina, consumidores (Olson, 1971: 165; traducción del autor). Se esperaría, entonces, que el status quo fuera defendido por pequeños grupos con capacidad de lobby ${ }^{25}$ pero con poco poder electoral, y que las reformas fueran apoyadas por grandes grupos pobremente o no organizados pero con mucho peso electoral. El razonamiento de Olson ayuda a explicar porqué tantas administraciones reformistas ganan elecciones aún cuando se les oponen poderosos grupos de interés.

Otra consideración importante con respecto a los costos y beneficios de los cambios de política económica es que aún si los costos de las reformas fueran altos y generalizados, los costos de no hacer nada (es decir, los costos de mantener el modelo heterodoxo-estatista) son probablemente mayores. "Las políticas ortodoxas no han of recido ninguna garantía de éxito económico, pero las políticas no ortodoxas que enfatizan el crecimiento a expensas de la estabilización y del ajuste (como en Perú luego de 1985) fueron una receta cierta para el desastre" (Remmer, 1993: 403; traducción del autor). Parece claro que los (heterodoxos y estatistas) gobiernos de Siles en Bolivia, Alfonsín en Argentina, García en Perú y Sarney en Brasil no habrían sido tan severamente castigados por los votantes si hubieran implementado las políticas que derrotaron la inflación y la recesión en otros países. Recientemente, Kurt Weyland desarrolló una explicación del apoyo popular a las reformas bajo crisis económicas profundas, concluyendo: "La inflación galopante coloca a muchos ciudadanos en el terreno de las pérdidas, lo que los induce a aprobar estrategias riesgosas de ajuste económico" (Weyland, 1996: 191; traducción del autor).

Las políticas ortodoxas y de libre mercado pueden haber afectado la declinación electoral por otros medios además de sus costos y beneficios económicos intrínsecos ("Otras variables (3)" en la figura I) ${ }^{26}$. Primero, estas políticas fueron aplicadas a menudo por equipos tecnocráticos capaces de generar confianza popular debido a su imagen de competencia y honestidad ${ }^{27}$. Segundo, los mensajes de apoyo a las reformas de fuentes influyentes y autorizadas (como eco- nomistas extranjeros y locales, funcionarios del FMI y del Banco Mundial, etc.) pueden haber provisto legitimidad a los programas de reforma. Otro factor muy importante fue el decepcionante desempeño económico previo de la mayoría de los países latinoamericanos, que generó demandas de cambio y contribuyó a la popularidad de las nuevas políticas. Además, la existencia de un ejemplo regional de reforma de mercado exitosa como Chile ayudó a convencer a muchos acerca de la viabilidad de la nueva estrategia económica. En varios países, como Argentina, Bolivia, Chile y Costa Rica, la liberalización de la economía fue emprendida por partidos previamente populistas o de centro-izquierda. El hecho de que estos partidos contaran con gran apoyo popular debe haber colaborado en parte al éxito electoral de las nuevas políticas. Finalmente, varios actores internacionales de orientación reformista como el FMI, el Banco Mundial y el gobierno de los EE.UU., otorgaron abundantes préstamos y ayuda a aquellos gobiernos que implementaron reformas de libre mercado, lo cual suavizó sus costos sociales. Algo parecido puede ser dicho con relación a los inversores extranjeros privados.

Se planteó la siguiente hipótesis: en los países latinoamericanos en la década del '80 y en la primera mitad de los '90, las políticas económicas ortodoxas y de libre mercado no estuvieron asociadas con un desempeño electoral peor por parte de los presidentes de la región que las políticas beterodoxas y estatistas (a igualdad de otros factores). Esta hipótesis fue empíricamente confirmada a través de varios modelos de regresión múltiple: ninguno de los coeficientes correspondientes a los cuatro indicadores de política económica confirman el paradigma tradicional. Contra sus expectativas, las políticas ortodoxas y de libre mercado no provocaron un peor desempeño electoral de los partidos en el poder: han tenido efectos nulos o positivos en el apoyo popular a los mismos. También se demostró que parte de efecto de la política económica sobre el desempeño electoral ocurre a través de variables de desempeño económico, particularmente la inflación. Se propusieron algunas explicaciones para estos resultados ${ }^{28}$. Estas explicaciones, con excepción de los efectos de la inflación sobre el desempeño electoral, no han sido empíricamente corroboradas. Constituyen afirmaciones hipotéticas potencialmente fructíferas para futuras investigaciones.

25. Los policy-makers en los países en desarrollo en los ' 80 "se enfrentaron con el hecho de que las filas opositoras al cambio estaban pobladas de beneficiarios del status quo: élites económicas sostenidas por las políticas existentes; grupos étnicos, regionales y religiosos favorecidos en las deci siones de asignación de recursos; agencias burocráticas y burócratas con poder regulatorio; élites políticas sostenidas por redes clientelares; organizaciones militares acostumbradas a gastar presupuestos generosos sin la debida rendición de cuentas" (Grindle and Thomas, 1991: 3).

26. Una explicación más detallada sobre este punto puede encontrarse en Gervasoni (1995: 28-32).

27. Debo Clark Reynolds la idea de que la gente por lo general con fía en los tecnócratas y piensa que son, a diferencia de los políticos, capaces y honestos.

28. Para una lúcida reseña de la literatura teórica sobre la tolerancia a las reformas económicas que supuestamente generan resistencia, ver Navarro (1995). 


\begin{tabular}{|c|c|c|c|c|c|c|c|c|}
\hline \multicolumn{9}{|c|}{$\begin{array}{l}\text { APÉNDICE: BASE DE DATOS } \\
\text { Tabla VIII. Datos de las variables independientes utilizados en los modelos } 1 \text { a } 4\end{array}$} \\
\hline PAIS & ADMINISTRACION & $\mathrm{DI}^{\mathrm{*}}$ & $\mathrm{COM}^{2}$ & PROT:" & $\mathrm{PE}^{+}$ & GC' & IIIPER. & PB M.' \\
\hline \multirow[t]{2}{*}{ Argentina } & Alfonsín & 4,10 & 232 & 4 & 4 & 0 & No & 4,6 \\
\hline & Menem & $-0,20$ & $13^{*}$ & 1 & 1 & 0 & Derrot. & 3,6 \\
\hline \multirow[t]{3}{*}{ Bolivia } & Siles & 13,80 & 7574 & 2 & 4 & 0 & No & 3,3 \\
\hline & Paz Estenssoro & 4,10 & 27 & 1 & 4 & 0 & Derrot. & 4,6 \\
\hline & Paz Zamora & 0,10 & 40 & 1 & 4 & 0 & No & 2,0 \\
\hline Brasil & Collor & 2,20 & 745 & 2 & 4 & 0 & No & 2.0 \\
\hline Chile & Aylwin & $-2,25$ & 7 & 1 & 2 & 0 & No & 2,5 \\
\hline \multirow{3}{*}{ Colombia } & Betancur & 3,50 & 17 & 5 & 4 & 1 & No & 3,3 \\
\hline & Barco & 1,55 & 18 & 4 & 4 & 1 & No & 3,5 \\
\hline & Gaviria & 1,85 & 31 & 1 & 3 & 1 & No & 2,5 \\
\hline \multirow[t]{3}{*}{ Costa Rica } & Monge & 2,55 & 9 & 4 & 5 & 0 & No & 3,3 \\
\hline & Arias & 3,30 & 24 & 2 & 5 & 0 & No & 3,5 \\
\hline & Calderón & 1,90 & 13 & 1 & 4 & 0 & No & 2,5 \\
\hline \multirow[t]{2}{*}{ R. Domin. } & Blanco & 1,55 & 26 & 4 & 4 & 0 & No & 3,3 \\
\hline & Balaguer & $-0,30$ & 33 & 3 & 4 & 0 & No & 3,5 \\
\hline \multirow[t]{2}{*}{ Ecuador } & lebres & 4,20 & 24 & 5 & 4 & () & No & 4,0 \\
\hline & Borja & $-2,45$ & 57 & 2 & 4 & 0 & No & 1,3 \\
\hline \multirow[t]{2}{*}{ El Salvador } & Duarte & 1,95 & 4 & 3 & 4 & 1 & No & 4,6 \\
\hline & Cristiani & 2,25 & 21 & 1 & 3 & () & No & 2,5 \\
\hline Guatemala & Сегеж & 2,35 & 33 & 2 & 2 & 1 & No & 2,4 \\
\hline \multirow{3}{*}{ Honduras } & Suazo & 8,50 & 1 & 5 & 4 & 0 & No & 3,3 \\
\hline & Azcona & 5,05 & 15 & 3 & 4 & 0 & No & 3,5 \\
\hline & Callejas & 6,65 & 19 & 1 & 3 & 0 & No & 2,5 \\
\hline \multirow{3}{*}{ Perú } & Ortega & 14,30 & 4220 & 5 & 5 & 1 & No & 3,5 \\
\hline & García & 5,10 & 1586 & 5 & 5 & 1 & No & 3,5 \\
\hline & Fujimori & $-0,50$ & 31 & 2 & 3 & 0 & Derrot. & 3,6 \\
\hline \multirow{2}{*}{ Uruguay } & Sanguinetti & 2,70 & 61 & 3 & 4 & 0 & No & 3,5 \\
\hline & Lacalle & 1,65 & 38 & 1 & 3 & 0 & No & 3,6 \\
\hline \multirow[t]{2}{*}{ Venezuela } & Lusinchi & 4,50 & 18 & 4 & 5 & 0 & No & 4,6 \\
\hline & P'érez & 0,40 & 27 & 2 & 4 & 0 & No & 2,0 \\
\hline \multicolumn{9}{|c|}{ 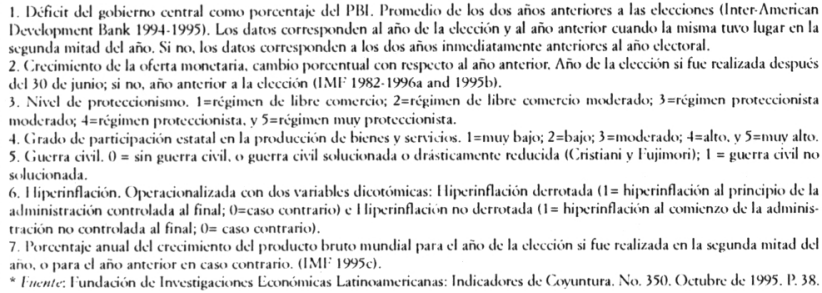 } \\
\hline
\end{tabular}

\section{REFERENCIAS}

ACuña, C. (1993): “Argentina. Hacia un Nuevo Modelo." Nueva Sociedad, No. 126, julio-agosto 1993: 11-24.

Agosin, M. (1992): "Las Experiencias de Liberalización Comercial en América Latina: Lecciones y Perspectivas." Pensamiento Iberoamericano, No. 21, enero-junio 1992: 13-29.

Agosin, M. and French-Davis, R. (1993): "Trade liberalization in Latin America." CEPAL Review, 0 (50), August 1993: 393-407.

ASAD, A. and Rajapatirana, S. (1993): "Trade Policy Reforms in Latin America and the Caribbean During the 1980s." World Bank. Working Paper. Washington DC.

BAER, W. (1994): "Privatization in Latin America." The World Economy, July 1994, V. 17 No. 4: 509-528.

BAER, W. and Birch, M. (1992): "Privatization and the Changing Role of the State in Latin America" New York. University Journal of International Law and Politics, Vol. 25, No. 1, Fall 1992: 1-25.

BAER, W. and Birch, M. (eds.) (1994): Privatization in Latin America. New Roles for the Public and Private Sectors. Praeger.

Banco Mundial (1993): America Latina y el Caribe. Diez Años Después de la Crisis de la Deuda. Banco Mundial. Oficina Regional de America Latina y el Caribe. Washington, D.C.

Canitrot, A. and Junco, S. (eds.). (1993): Macroeconomic Conditions and Trade Liberalization. Inter- American
Development Bank-Torcuato Di Tella Institute. Washington DC, 1993.

Dean, J., Seema, D. and Riedel J. (1994): “Trade Policy Reform in Developing Countries since 1985. A Review of the Evidence." World Bank Discussion Papers. Washington DC.

Devlin, R. (1993): "Privatizations and Social Welfare." CEPAL Review, No. 49, April 1993: 155-180.

DoRnBusCH, R. (1991): Structural Adjustment in Latin America. Woodrow Wilson International Center for Scholars. Washington, D.C.

DuCH, Raymond. (1993): “Tolerating Economic Reform: Popular Support for Transition to a Free Market in the Former Soviet Union." American Political Science Review, Vol. 87, No. 3, September 1993: 590-608.

EASTERLY W., Rodriguez C. and Schmidt-Hebbel, K. (1994): "Overview." In Easterly W., Rodriguez C. and SchmidtHebbel, K.: Public Deficits and Macroeconomic Performance. A World Bank publication. Oxford University Press.

EASTERLY W. and Schmidt-Hebbel, K. (1994): "Synthesis and Methodology." In Easterly W., Rodriguez C. and Schmidt-Hebbel, K.: Public Deficits and Macroeconomic Performance. A World Bank publication. Oxford University Press.

ECONOMIC COMISSION FOR LATIN AMERICA AND THE CARIBBEAN (1980 to 1997): Economic Survey of Latin America and the Caribbean. UN. Santiago de Chile.

EDWARDS, S. (1994ª): "Macroeconomic Stabilization in Latin America: Recent Experience and Some Sequencing Issues." NBER Working Paper No. 4697. Cambridge, MA.

- (1994b): "Trade and Industrial Policy Reform in Latin America." NBER Working Paper No. 4772. Cambridge, MA.

- (1995): Crisis and Reform in Latin America. From Despair to Hope. A World Bank Book. Oxford University Press.

Geddes, B. (1995): "The Politics of Economic Liberalization." Latin American Research Review, Vol. 30, N. 2, 1995: 195-214.

Gervasoni, C. (1995): "Economic Policy and Electoral Performance in Latin America, 1982-1995.” M.A.Thesis, Center for Latin American Studies, Stanford University.

Glade, W. (ed.). (1986): State Shrinking. A Comparative Inquiry into Privatization. Institute of Latin American Studies, University of Texas at Austin, Austin.

- (1991): Privatization of Public Enterprises in Latin America. ICS Press, San Francisco.

Grindle, M. and Thomas, J. (1991): Public Choices and Policy Change. The Political Economy of Reform in Developing Countries. The Johns Hopkins University Press.

GUSTAFson, L. (ed.). (1994): Economic Development Under Democratic Regimes: Neo-liberalism in Latin America. Praeger.

HAgGaRd, S. and Kaufman, R. (eds.). (1992): The Politics of Economic Adjustment. International Constraints, Distributive Conflicts, and the State. Princeton University Press. Princeton. 
HagGard, S. and Webb, S. (1994): “Introduction." In Haggard, S. and Webb, S. (eds.): Voting for Reform: Democracy, Political Liberalization and Economic adjustment. World Bank. Washington, D.C. Oxford University Press.

Hamilton, L. (1992): Regression with Graphics. A Second Course in Applied Statistics. Duxbury Press.

Hojman, D. (1994): "The Political Economy of Recent Conversions to Market Economics in Latin America." Journal of Latin American Studies, February 1994, V. 26 No.1: 191-219.

INTER-AMERICAN DEVELOPMENT BANK (1994): Economic and Social Progress in Latin America. 1994 report. The Johns Hopkins University Press. Washington D.C.

- (1995): Economic and Social Progress in Latin America. 1995 report. The Johns Hopkins University Press. Washington D.C.

INTERNATIONAL MONETARY FUnd (1982 to 1996a): International Financial Statistics. International Monetary Fund. Washington, D.C.

- (1995b): International Financial Statistics Yearbook. International Monetary Fund. Washington, D.C. (1995c): Perspectivas de la Economía Mundil. International Monetary Fund. Washington, D.C.

JoHnson, B. and Sheehy, T. (1995): The Index of Economic Freedom. The Heritage Foundation. Washington, D.C. Kelly DE EsCoBAR, J. (comp.). (1985): Empresas del Estado en América Latina. Ediciones IESA, Caracas.

Krueger, A. (1993):. Political Economy of Policy Reform in Developing Countries. The MIT Press.

Latin FinanCE (1991-1995): "Privatization Update." Latin Finance, January 1991-June 1995.

- (1991): Privatization in Latin America. A Latin Finance Supplement. March 1991.

- (1995a): Privatization in Latin America. A Latin Finance Product Supplement. January-February 1995.

- (1995b): Utilities in Latin America. A Latin Finance Industry Supplement. April 1995.

LEWIS-BECK, M. (1990): Economics and Elections. The Major Western Democracies. The University of Michigan Press. Ann Arbor.

LIEBERMAN, I. (1994): "Privatization in Latin America and Eastern Europe in the Context of Political and Economic Reform." The World Economy, July 1994, V. 17 No. 4: 551-575.

LynCH, E. (1994): "Bolivia and The New Economic Policy of Victor Paz Estenssoro.” In Gustafson, L.(ed.), 1994.

Nelson, J. (1992): "Poverty, Equity, and the Politics of Adjustment.” In Haggard, S. and Kaufman, R. (eds.) 1992.

Nelson, J. (ed.). (1990): Economic Crisis and Policy Choice. The Politics of Adjustment in the Third World. Princeton University Press.

NoHLEN, D. (coord.). (1993): Enciclopedia Electoral Latinoamericana y del Caribe. San José: Instituto Americano deDerechos Humanos.

O'Donnell, G. (1973): Modernization and BureaucraticAuthoritarianism. Studies in South American Politics. Institute of International Studies. University of California, Berkeley.
Olson, M. (1971): The Logic of Collective Action. Public Goods and the Theory of Groups. Schocken Books. New York.

- (1982): The Rise and Decline of Nations. Economic Growth, Stagflation, and Social Rigidities. Yale University Press.

Petras, J. (1991): “El ‘Milagro Económico’ Chileno: Crítica Empírica.” Nueva Sociedad, No. 113, mayo-junio 1991: 146-157.

PRZEWORSKI, A. (1991): Democracy and the market. Political and Economic Reforms in Eastern Europe and Latin America. Cambridge University Press.

PrZEWORSKI, A. and Stokes, S. (1993): "Political Dynamics of Economic Reforms: Six Facts in Search of an Explanation." Paper presented in the Conference on Political Dynamics of Economic Reforms, University of Chicago, May 14-16, (1993):.

Remmer, K. (1991): "The Political impact of Economic Crisis in Latin America in the 1980's." American Political Science Review, V. 85 No. 3, September 1991: 777-800.

- (1993): "The Political Economy of Elections in Latin America, 1980-1991." American Political Science Review, V. 87 No. 2, June (1993): 393-407.

RiaL, J. y Zovatto, D. (eds.) (1992): Una Tarea Inconclusa: Elecciones y Democracia en América Latina: 1988-1991. Instituto Interamericano de Derechos Humanos - Centro de Asesoría y Promoción Electoral. San José de Costa Rica.

Rodrik, D. (1996): "Understanding Economic Policy Reform." Journal of Economic Literature. Vol. XXXIV, March 1996: 9-41.

Sanchez, M. y Corona, R. (eds.) (1993): Privatization in Latin America. Inter-American Development Bank-The Johns Hopkins University Press. Washington, D.C.

SmITH, W., Acuña, C. y Gamarra, E. (1994a): Latin American Political Economy in the Age of Neoliberal Reform. New Brunswick: Transaction Publishers.

- (1994b): Democracy, Markets and Structural Reform in Latin America. Argentina, Bolivia, Brasil, Chile and Mexico. New Brunswick: Transaction Publishers.

Stokes, S., Przeworski, A. y Buendía Laredo, J. (1997): "Opinión Pública y Reformas de Mercado: las Limitaciones de la Interpretación Económica del Voto." Desarrollo Económico (Buenos Aires), Vol. 37, No. 145, abirl-junio 1997: 31-56.

Sunkel, O. y Zuleta, G. (1990): “Neo-structuralism vs. Neo-liberalism in the 1990's." CEPAL Review, No. 42, December 1990: 35-51.

The Economist Intelligent UNit Several years. Country Profile. Dominican Republic, Haiti, Puerto Rico. 1986/871990/91. London.

- Several years. Country Profile. Ecuador. 1986/87-1992/ 93. London.

- Several years. Country Profile. Guatemala, El Salvador, Honduras. 1986/87-1992/93. London.

- Several years. Country Profile. Guatemala, El Salvador. (1993):/94-1994/95. London.

- Several years. Country Report. Dominican Republic, Haiti, Puerto Rico. No. 2, 1986-No. 4, 1991. London. 
- Several years. Country Report. Ecuador. No. 2, 1986-No. 4, 1992. London.

- Several years. Country Report. Guatemala, El Salvador, Honduras. No. 2, 1986-No. 4, 1994. London.

- Several years. Quarterly Economic Review of Guatemala, El Salvador, Honduras. No. 1, 1983-No. 1, 1986. London.

U.S. Department of State (1989): Country Reports on Economic Policy and Trade Practices. U.S. Government Printing Office, Washington, D.C.

Weyland, K. (1996): "Risk Taking in Latin American Economic Restructuring: Lessons from Prospect Theory." International Studies Quarterly, (1996) 40: 185-208
Williamson, J. (de.). (1990a): Latin American Adjustment: How Much Has Happened? Washington, D.C.: Institute of International Economics.

- (1990b): The Progress of Policy Reform in Latin America. Washington, D. C.: Institute of International Economics.

WORTMAN, M. (1990): Privatization in Latin America. New Competitive Opportunities and Challenges. Business International Corporation. New York.

\section{RESUMEN}

Los argumentos sobre la impopularidad de las políticas ortodoxas y de libre mercado en el mundo en desarrollo condujeron a muchos académicos a pensar que su implementación en los países democráticos de América Latina resultaría en un castigo electoral a los gobiernos (y, por lo tanto, implicaría la insostenibilidad de esas políticas). Una línea más reciente de la literatura plantea que los costos sociales y electorales de las políticas ortodoxas y de libre mercado han sido considerablemente más bajos que lo esperado, especialmente cuando se los compara con los costos del mantenimiento de políticas heterodoxas y estatistas. Usando datos sobre 30 gobiernos latinoamericanos elegidos democráticamente después del comienzo de la crisis de la deuda, se pone a prueba (vía análisis de regresión múltiple) la hipótesis de que las políticas ortodoxas y de libre mercado han estado asociadas con iguales (o mejores, pero nunca peores) resultados electorales para los gobiernos que las políticas heterodoxas y estatistas. Las conclusiones son que la ortodoxia monetaria está fuertemente correlacionada con el apoyo electoral, mientras que el proteccionismo y los déficit fiscales son neutrales o están asociados con pérdidas electorales. El grado de participación del estado en la producción no tiene un efecto estadísticamente significativo sobre el desempeño electoral de los gobiernos. Estos resultados tienden a confirmar la hipótesis y plantean un serio cuestionamiento a la opinión tradicional de que los votantes castigan las reformas económicas.

Palabras clave: Reformas económicas, Política económica, Elecciones, Desempeño electoral, Resultados electorales, América Latina.

\section{ABSTRACT}

Arguments about the unpopularity of orthodox and free-market policies in the developing world led many scholars to think that their implementation in democratic Latin American countries would result in the electoral punishment of the incumbent administrations (and, therefore, in the discontinuation of those policies). More recent literature suggests that the social and electoral costs of orthodox and free-market policies are considerably lower than expected, especially when compared to the costs of maintaining heterodox and statist policies. Drawing on data for 30 democratic Latin American presidential administrations elected after the outset of the debt crisis, the hypothesis that orthodox and free-market policies have been associated with equal (or better, but never worse) electoral results for incumbents than heterodox and statist polices is tested through multiple regression analysis. The conclusions are that monetary orthodoxy is strongly correlated with electoral gains, while protectionism and fiscal deficits are neutral or associated with electoral losses. The degree of state involvement in the productive process does not have significant effects on the electoral performance of incumbent administrations. These results lend considerable support to the hypothesis, and pose a serious challenge to the traditional view that voters punish market reforms.

Key Words: Economic reforms, Economic policy, Elections, Electoral performance, Electoral results, Latin America. 